Cahiers Charlevoix

Études franco-ontariennes
Cahiers Charlevoix Études franco-ontariennes

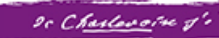

\title{
Fourrures, commerce et guerre : Verchères de Boucherville dans le Haut-Canada (1803-1816)
}

\section{Gaétan Gervais}

Volume 5, 2002

URI : https://id.erudit.org/iderudit/1039353ar

DOI : https://doi.org/10.7202/1039353ar

Aller au sommaire du numéro

\section{Éditeur(s)}

Société Charlevoix

Presses de l’Université d'Ottawa

\section{ISSN}

1203-4371 (imprimé)

2371-6878 (numérique)

Découvrir la revue

Citer cet article

Gervais, G. (2002). Fourrures, commerce et guerre : Verchères de Boucherville dans le Haut-Canada (1803-1816). Cahiers Charlevoix, 5, 153-228.

https://doi.org/10.7202/1039353ar
Résumé de l'article

Gaétan Gervais porte son regard sur un personnage issu d'une famille appartenant à la noblesse canadienne. Il s'agit de Verchères Boucher de Boucherville qui, durant la période 1803-1816, mena des activités commerciales dans le Haut-Canada et, particulièrement, dans les environs d'Amherstburg, un fort britannique situé en aval de Détroit. Par l'étude du Journal qu'il laissa, notre collègue apprécie la place que tenait encore le commerce des fourrures et examine les rouages du commerce de détail, mais, surtout, il peut montrer comment, pour maintenir son statut social, la noblesse canadienne devait s'appuyer sur des réseaux solides de connaissances et de relations et, dans le cas de Boucherville, comment ses relations avec un homme d'affaires en vue, Quetton de Saint-Georges, et d'autres aristocrates et militaires que sa famille avait fréquentés, lui pavèrent la voie dans le monde du commerce de détail au temps de la Guerre de 1812. 


\section{FOURRURES, COMMERCE ET GUERRE: VERCHÈRES DE BOUCHERVILLE Dans le Haut-Canada (1803-1816)}

Gaétan Gervais

Département d'histoire

Université Laurentienne, Sudbury 


\section{SOMMAIRE}

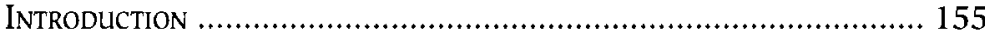

I - Le Haut-Canada au début du XIX' SIÈCLE ………….............. 157

II - Famille, relations et COMMERCE DES FOURRuRes 1803-1804 .... 166

A. La noblesse canadienne .......................................... 167

B. La famille de Boucherville ......................................... 177

C. Verchères de Boucherville dans le Nord-Ouest .............. 181

III - BoucheRVILLE ET LE COMMERCE DE DÉTAIL 1804-1812 .............. 188

A. Économie et commerce de détail ................................. 188

B. Le commis de Quetton de Saint-Georges ....................... 196

C. Boucherville à son propre compte …………..................... 203

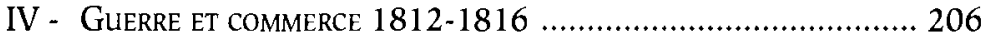

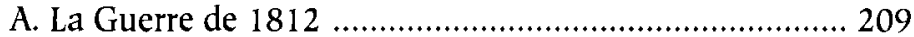

B. Le commerce en temps de guerre .................................. 216

C. Vaines tentatives pour reprendre le commerce .............. 222

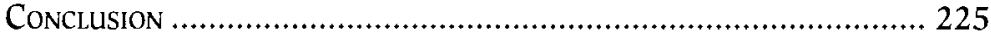




\section{FOURRURES, COMMERCE ET GUERRE: VERCHÈRES DE BOUCHERVILLE DANS le Haut-Canada (1803-1816)}

\section{INTRODUCTION}

Thomas-René Boucher de Boucherville (1784-1857), qui ajouta tardivement le prénom de Verchères à son patronyme, appartenait à une illustre famille de la noblesse canadienne ${ }^{1}$. Au début du XIX ${ }^{e}$ siècle, ce groupe nobiliaire jouissait encore d'un grand prestige social, certes, mais il ne possédait plus de statut juridique distinct, ce qui l'obligeait à compter beaucoup sur ses relations pour tenir son rang.

\footnotetext{
${ }^{1}$ Pour la biographie de Thomas-René-Verchères de Boucherville, voir Frederick H. Armstrong, «Boucher de Boucherville, Thomas-René-Verchères", dans Dictionnaire biographique du Canada [désormais: DBC] Volume VIII de 1851 à 1860, [Québec], Presses de l'Université Laval, [c1985], pp. 111-112; "Les Disparus", dans Bulletin des recherches historiques XXXIV, $\mathrm{n}^{\circ} 10$, octobre 1928, p. 622; René Dionne, Histoire de la littérature franco-ontarienne des origines à nos jours. Tome 1. Les origines françaises (1610-1760). Les origines franco-ontariennes (1760-1865), Sudbury, Prise de parole, 1997, pp. 211-216. Au cours de cet essai, le personnage principal est appelé tantôt Thomas-René Boucher de Boucherville, tantôt Thomas Boucher ou Thomas de Boucherville, tantôt Verchères de Boucherville, tantôt, si le contexte ne prête pas à confusion, tout simplement Boucherville.
} 
Depuis les débuts de la colonie, cette élite locale avait assuré sa survie économique grâce au patronage de l'État, dispensé sous forme de charges rétribuées, de pensions, de cadeaux ou de seigneuries. Il s'agissait d'une classe sociale qui avait aussi survécu grâce à l'exploitation de ses terres seigneuriales et à sa participation au commerce des fourrures. Combien de nobles, en effet, avaient tenté de s'enrichir dans ce trafic. Car, dans les colonies, la noblesse pouvait, sans déroger à son rang, s'engager ouvertement dans des activités économiques lucratives.

Retrouver Thomas-René-Verchères Boucher de Boucherville comme jeune commis travaillant dans le commerce des fourrures ou dans la vente au détail n'avait done rien d'étonnant. Car ces activités mercantiles s'inscrivaient en parfaite continuité avec la pratique de ses ancêtres et avec les habitudes de la noblesse canadienne. Ainsi, Boucherville, dans ses jeunes années, chercha-t-il à faire fortune dans le commerce, avant de se marier, en 1819, et de suivre ensuite la carrière de seigneur, de juge de paix et de major de milice.

Pendant la période où il fréquenta le Haut-Canada, entre 1803 et 1816 , Verchères de Boucherville fut le témoin, à vrai dire peu critique, des transformations de l'économie canadienne. Il put d'abord observer certains changements en cours dans le domaine des fourrures, lors de son bref séjour dans le Nord-Ouest au service d'une société appartenant à un groupe de marchands montréalais dirigé par le célèbre Alexander Mackenzie (1803-1804). D'autres mutations se produisaient alors dans le secteur commercial, à l'époque où Boucherville était commis chez le marchand Laurent Quetton de Saint-Georges (18041808). Le jeune fils de famille, qui au début cuvra dans le commerce de détail à titre de commis, travailla d'abord dans les environs de Toronto, alors appelé York, puis, après 1806, à Amherstburg. Il se constitua ensuite, sous le 
parrainage de son ancien patron, marchand à son propre compte (1808-1812). La Guerre de 1812 lui apporta d'abord le succès financier, mais, par la suite, des difficultés surgirent qui le ruinèrent (1815-1816).

\section{I - Le Haut-Canada au début du XiX ${ }^{e}$ siècle}

Dans le Haut-Canada, à cette époque, un régime économique se mourait, un autre naissait. Â une économie basée sur le commerce des fourrures, sur la fréquentation indispensable des Amérindiens, sur l'importance des relations étroites avec l'armée britannique, succédait un régime fondé sur la colonisation, l'agriculture, la coupe du bois et le commerce, en attendant la création des manufactures et des industries à la fin du XIX ${ }^{e}$ siècle. Dans la région du Saint-Laurent et des Grands Lacs, l'échange de pelleteries ou de produits agricoles contre des marchandises manufacturées représentait peu en valeur, mais constituait au début du siècle la principale activité commerciale de la colonie. Le trafic des fourrures vivait alors ses dernières heures, bientôt supplanté par le commerce du bois, un secteur en pleine expansion grâce au blocus continental décrété par Napoléon en 1806 et grâce à une demande croissante de bois en Angleterre. Ainsi, dans la nouvelle colonie du Haut-Canada, fondée en 1791, la part des échanges commerciaux dans l'économie générale restait modeste. Néanmoins, celle-ci représentait le prolongement au cœur du continent de la zone d'influence économique de Montréal.

À la fin du XVIII ${ }^{e}$ siècle et au début du XIX', le monde occidental subissait une grande transformation, appelée la révolution atlantique par les historiens de la période, une rupture qui marquait le passage entre l'Ancien Régime et la société moderne. Sous le nom de "révolution industrielle» (caractérisée par l'énergie du charbon, les machines à vapeur, le machinisme, les manufactures de textile, les 
nouveaux modes de transport, les technologies nouvelles), une mutation économique radicale bouleversa la société, poussant à l'avant-scène la bourgeoisie industrielle, avec ses idées révolutionnaires sur la liberté du commerce, sur la suppression des tarifs et sur la promotion des manufactures. Bénéficiaire des monopoles si typiques du capitalisme marchand et des doctrines économiques du mercantilisme, l'ancienne bourgeoisie marchande, depuis longtemps alliée aux classes dominantes de l'Ancien Régime sur lesquelles régnait la noblesse, reculait devant la bourgeoisie industrielle montante. Enrichie dans la production des biens plutôt que dans les échanges, cette nouvelle classe aspirait à déloger non seulement les ordres privilégiés d'hier, c'est-à-dire le clergé et la noblesse, mais aussi les capitalistes marchands. Au pied de la nouvelle structure sociale se constituait peu à peu un prolétariat, à mesure que se multipliaient, dans les agglomérations urbaines, des manufactures employant une nombreuse main-d'œuvre salariée.

Dans la sphère des idées, les forces déchaînées par la Révolution américaine (1776-1783) et par la Révolution française (1789-1799) ont préparé la diffusion de nouveaux courants idéologiques (le libéralisme, le nationalisme, la démocratie) dans le monde occidental et au-delà. Ces idées corrosives sapaient partout les bases des régimes politiques anciens et remettaient en cause les privilèges qui avaient jusqu'alors cimenté les liens unissant les classes dominantes. Ainsi, les changements économiques et sociaux se répercutèrent directement dans le domaine politique.

Le Haut-Canada ne possédait alors qu'une faible population. Ses habitants, presque tous des ruraux, vivaient en autarcie relative sur leurs terres. Il leur fallut du temps pour produire des surplus agricoles et pour accéder ainsi à l'économie de marché. La région de l'Assomption (devenue Sandwich, plus tard Windsor) reçut ses premiers colons, des Canadiens, en 1749, puis les loyalistes arrivèrent 
Verchères de Boucherville dans le Haut-CANAda

dans le Haut-Canada par milliers dans les années 1780. Le peuplement de la colonie s'étendait au début du XIX ${ }^{e}$ siècle en long ruban, sur une étroite bande de terres se déroulant au nord du fleuve Saint-Laurent et des lacs Ontario et Érié. La population, estimée à environ 6000 en 1785 , atteignait près de 40000 personnes vers 1800 . Au début de la guerre, en 1812, la population pouvait s'élever à 80000 âmes, peut-être moins.

La province de Québec, d'abord constituée en 1763 par la Proclamation royale, agrandie en 1774 par l'Acte de Québec, puis amenuisée en 1783 par le traité de Versailles, fut scindée en 1791 par l'Acte constitutionnel pour former le Haut et le Bas-Canada. Le premier lieutenant-gouverneur du Haut-Canada, John Graves Simcoe, avait pour programme d'établir dans la colonie une aristocratie foncière qui, comme en Angleterre, assurerait le maintien des valeurs britanniques contre les exemples néfastes de révolution, de républicanisme et de démocratie, répandus depuis la France et les États-Unis. Pour constituer cette classe terrienne, le gouvernement colonial haut-canadien distribua généreusement ses terres, ce qui entraîna des abus certains. Car les bénéficiaires de ces concessions spéculaient plus qu'ils ne colonisaient. De plus en plus, les privilèges accordés aux aristocrates et aux militaires venus d'Europe furent dénoncés par leurs adversaires, les réformistes, qui s'en prirent à ce réseau d'alliances et de patronage, appelé le Family compact à partir des années 1820 . Par ce régime de favoritisme, le gouvernement choisi par le lieutenant-gouverneur cherchait à monopoliser les places et la richesse en faveur de ses seuls amis. Dans le BasCanada, où régnait la clique du château, la noblesse canadienne s'allia souvent, par sa participation aux milices et par des alliances matrimoniales, à l'armée britannique et au réseau des familles de quelques grands marchands, dans l'espoir de recevoir ensuite des places, des contrats de fourniture et divers honneurs. 
Les faveurs du régime, les relations de la noblesse canadienne avec les militaires, la circulation d'idées nouvelles, voilà autant de facteurs qui ont fini par faire naître, même dans le Haut-Canada officiellement loyaliste, un courant réformiste que les autorités taxèrent rapidement de subversion américaine.

Le contentieux de la Grande-Bretagne avec les ÉtatsUnis était ancien et lourd. Après la Guerre d'Indépendance (1776-1783) et malgré le traité de paix signé à Versailles, les Britanniques continuèrent d'occuper les postes de l'Ouest (Oswegatchie, qui deviendra Ogdensburg, sur le Saint-Laurent supérieur, Oswego et Niagara sur le lac Ontario, Presque Île, aujourd'hui Érié, et Sandusky, sur le lac Érié, plus les deux importants postes de Détroit et de Michillimakinac), en attendant l'exécution de certaines clauses du traité de 1783 (voir la CARTE I). La GrandeBretagne justifia ses délais par des prétextes: au début, le besoin de protéger les intérêts des marchands dans le commerce des fourrures, ensuite l'obligation morale de défendre les Amérindiens alliés, enfin les réclamations non satisfaites des loyalistes demandant le remboursement des dettes et la restitution des propriétés confisquées. Mais surtout, la cession de ces postes embarrassait la GrandeBretagne qui, en 1783, avait honteusement laissé pour compte ses alliés amérindiens qui, vivant au sud des Grands Lacs, étaient désormais soumis aux volontés indépendantes des divers États américains. À la suite du traité de Jay (1794), les postes furent finalement abandonnés au début de $1796^{2}$. Les militaires britanniques de Michillimakinac, un fort situé à l'entrée du lac Michigan, se replièrent sur l'île Saint-Joseph, au nord du lac Huron, et ceux de Détroit traversèrent la rivière et s'établirent en

${ }^{2}$ A.L. Burt, The United States, Great Britain and North America from the Revolution to the Establishment of Peace after the War of 1812, New Haven, Yale University/Toronto, Ryerson Press, 1940, xvi-448 p. Sur les postes de l'Ouest et le traité de Jay en 1794, voir surtout les chapitres VI ( The Retention of the Western Posts», pp. 82-105) et VIII («Jay's Treaty», pp. 141-165). 
CARTE I

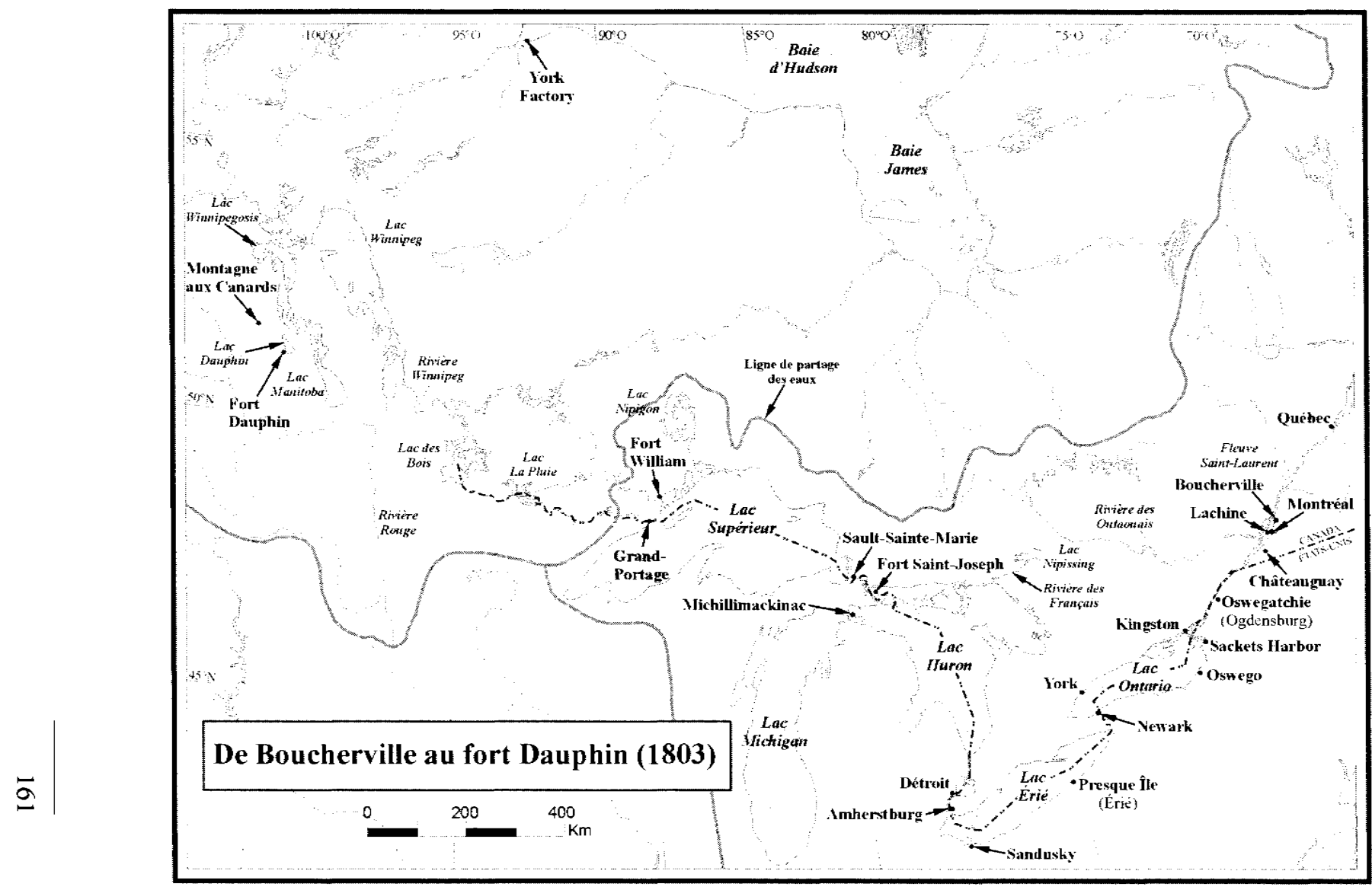

Réalisation LL Lariviere (Ǵographie. Université Laurentienne) 


\section{CARTE II}

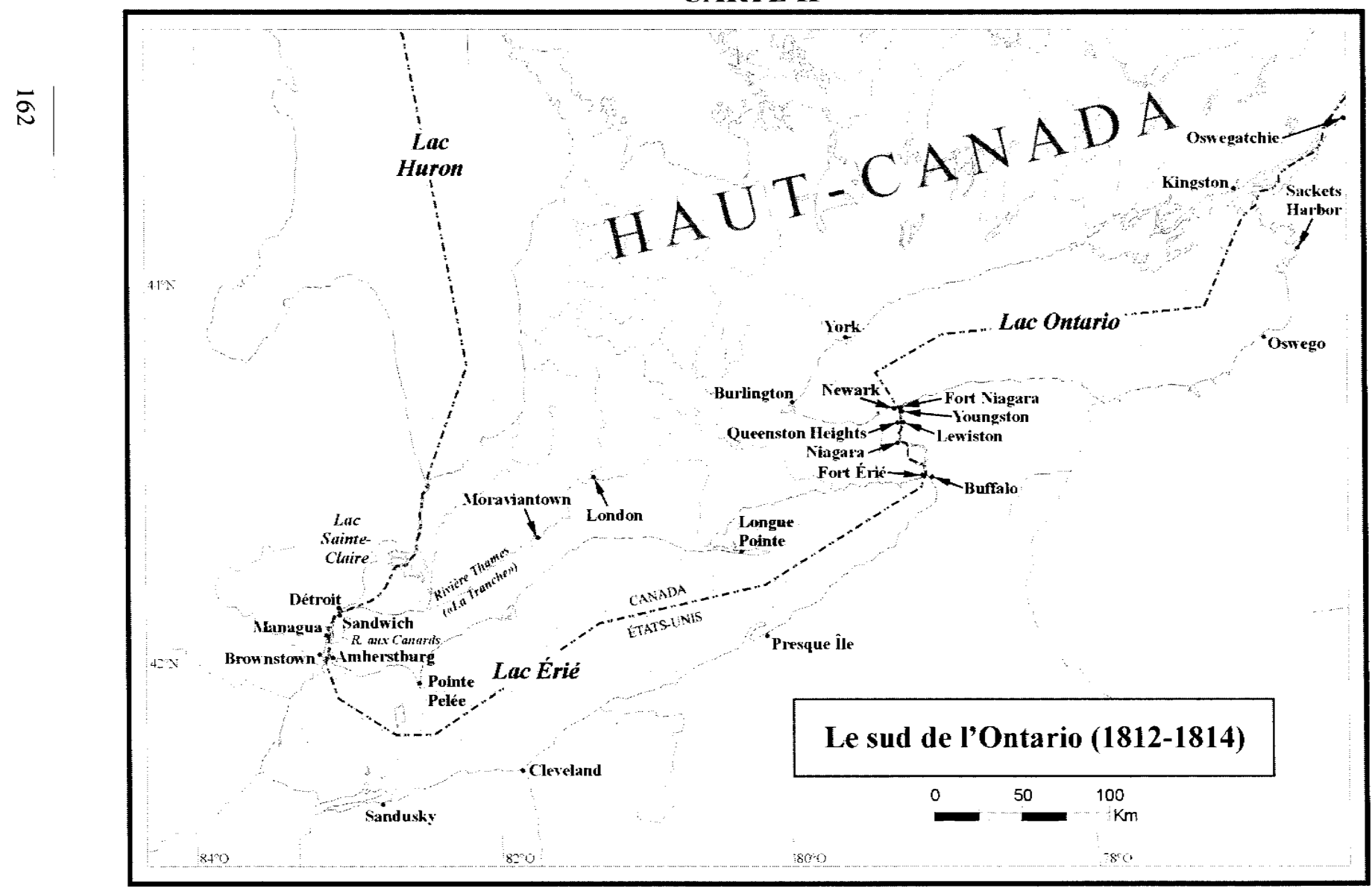

Réalisation : L. L. Lariviere (Géographie. Universié Laurentienne) 
aval de la colonie de l'Assomption, à Amherstburg, où ils érigèrent le fort Malden (voir la CARTE II) ${ }^{3}$.

Les conflits européens, après 1806 surtout, poussèrent plusieurs fois la Grande-Bretagne et les États-Unis au bord de la guerre. En outre, les Britanniques, comme les Français avant eux, avaient continué de cultiver, par un régime d'alliances et de remises de cadeaux, des complicités avec les tribus amérindiennes de la région des Grands Lacs. Les Américains soupçonnaient les Britanniques d'en profiter pour fomenter contre les États-Unis la révolte les Amérindiens. Ceux-ci se heurtaient souvent aux colons américains dont le peuplement ne cessait d'empiéter sur leurs terres. Quand sonna l'heure de la guerre, en 1812, les Amérindiens, dirigés par le grand chef potéouatami connu sous le nom de Tecumseh, furent au rendez-vous, aux côtés des Britanniques.

À l'époque, la menace de guerre fut le souci constant des autorités civiles et militaires du Haut-Canada. Parmi les dangers, il fallait bien commencer par la population même de la colonie, composée en grande partie de colons arrivés récemment des États-Unis (les late loyalists), très nombreux, surtout dans le Sud-Ouest, et forcément teintés par les idées républicaines et démocratiques répandues chez les Américains. Les autorités redoutaient beaucoup le manque de loyauté des colons haut-canadiens. Ces craintes étaient fondées, comme on put le constater quand on voulut lever les milices en 1812 .

Le début du XIX ${ }^{e}$ siècle fut ainsi une période de transition. Dans le Haut-Canada, on assistait au déclin du commerce des fourrures, alors que l'agriculture, et très tôt les

\footnotetext{
${ }^{3}$ Pour une brève histoire du fort Malden, appelé fort Amherstburg avant 1815, voir Dennis Carter-Edwards, «Defending the Straits: The Military Base at Amherstburg», dans K.G. Pryke et L.L. Kullisek (s.d.), The Western District. Papers from the Western District Conference, [Windsor], Essex County Historical Society/Western District Council, «Essex County Historical Society Occasional Papers» 2, 1983, pp. 33-41.
} 
exportations agricoles, commençaient d'augmenter. Mais l'enrichissement par le sol pouvait-il faire naître une aristocratie foncière vivant "noblement", c'est-à-dire de ses terres? Pour Simcoe, la noblesse canadienne, qui existait depuis le Régime français, préfigurait la classe terrienne qu'il rêvait d'établir dans le Haut-Canada. Pourtant, ni les seigneurs du Bas-Canada, ni les grands spéculateurs fonciers du Haut-Canada, ne réussirent à rassembler les vastes domaines de terres qui auraient pu soutenir le style de vie aristocratique dont ils rêvaient. La nécessité économique avait contraint les uns et les autres, au fil des ans, d'aliéner leurs terres. Au milieu du $\mathrm{XIX}^{\mathrm{e}}$ siècle, les dernières manifestations de ces ambitions s'effondrèrent. Ni dans le Haut, ni dans le Bas-Canada, on n'avait réussi à créer cette riche classe de propriétaires fonciers. La noblesse canadienne devait donc trouver ailleurs les moyens de sa survie économique. En plus de chercher dans le domaine des fourrures, elle se tourna du côté de l'armée britannique. La noblesse canadienne avait souvent exercé, depuis l'époque de la Nouvelle-France et encore au début du XIX ${ }^{\mathrm{e}}$ siècle, le métier des armes, soit dans l'armée, soit dans la milice. Ces services importaient d'autant plus qu'à l'époque, dans les colonies nord-américaines, l'armée britannique, par ses dépenses et ses investissements, restait le principal acteur de la vie économique. Ainsi, cette économie coloniale, dans son ensemble, restait sous la dépendance du gouvernement britannique, notamment de l'armée ${ }^{4}$.

Sur certaines de ces questions, nous disposons d'un document intéressant, le Journal de Thomas-René-Verchères Boucher de Boucherville 5 . Il s'agit de «mémoires», même

\footnotetext{
${ }^{4}$ Douglas McCalla, Planting the Province. The Economic History of Upper Canada 1784-1870, Toronto, Ontario Historical Studies Series/University of Toronto Press, [c1993], pp. 17-18.

${ }^{5}$ «Journal de M[onsieur] Thomas Verchères de Boucherville dans ses voyages aux pays d'en haut, et durant la dernière guerre avec les Américains, 1812[18]13» [désormais: [VB], dans le Canadian Antiquarian and Numismatic Journal, Troisième série - volume III, $\mathrm{n}^{\text {os }} 1$ à 4, [1900], ix-167 p. Le journal est
} 
si le document est abusivement appelé «journal». Le texte, daté de 1847 , raconte des événements survenus quelques décennies plus tôt, de 1803 à 1816. Le document circula dans la famille Boucher de Boucherville, mais ne fut publié qu'en 1900, à Montréal. L'auteur, qui déclare écrire ses souvenirs à l'intention de ses petits-enfants, indique que le Journal manque de détails, "[s]es notes ayant été perdues» (JVB 64). Le travail porte en sous-titre: «dans ses voyages aux pays d'en haut, et durant la dernière guerre avec les Américains 1812-[18]13». Le Journal se divise en deux parties: la première décrit le voyage de ThomasVerchères de Boucherville dans "les pays d'en haut", en fait au Nord-Ouest, dans le futur Manitoba (pp. 1-37), et ses activités mercantiles de 1804 à 1811 (pp. 38-67); la seconde traite de la Guerre de 1812 (pp. 68-167).

La dimension autobiographique du Journal comptera ici pour peu, alors que, dans la mesure où le permet cette source, la présente étude suivra de près les activités économiques de Boucherville, notamment dans les rapports qu'il cultive avec les élites politiques et militaires de la colonie pour aider son commerce. Un des aspects intéressants que le Journal permet d'examiner, c'est justement la pratique du commerce de détail selon l'expérience qu'en fait un jeune marchand dans le contexte d'une économie coloniale comme celle du Haut-Canada au début du XIX siècle. Dans ce milieu, la vente au détail touche encore peu l'ensemble de la population, la plupart des colons ne

publié en français dans ce périodique anglais de Montréal. René Dionne, dans son Anthologie de la littérature franco-ontarienne des origines à nos jours. Tome 1: les origines françaises (1610-1760). Les origines franco-ontariennes (17601865), Sudbury, Prise de parole, 1997, a publié trois extraits de ce Journal, pp. 427-438. Une version anglaise a aussi été publiée: $A$ Merchant's Clerk in Upper Canada: the Journal of Verchères de Boucherville, 1804-1811, traduction de W.S. Wallace, Toronto, 1935, puis à nouveau en anglais en 1940 à Chicago par Milo Milton Quaife: "The Chronicles of Thomas Verchères de Boucherville», dans War on the Detroit: the Chronicles of Thomas Verchères de Boucherville and the Capitulation, by an Ohio Volunteer, Chicago, Lakeside Press, 1940, pp. 1-178. 
produisant pas de surplus, ayant peu recours aux liquidités de monnaie et n'achetant que les indispensables objets manufacturés ou les produits importés qu'ils ne pouvaient produire eux-mêmes. C'est une économie de dépendance, non monétaire, agricole, où le transport des marchandises est peu développé, en somme une économie d'Ancien Régime. Dans l'économie haut-canadienne, les activités d'échange relevaient du capitalisme marchand et faisaient bon ménage avec les intérêts des classes dirigeantes traditionnelles.

Ce Journal peut donc servir de guide à l'étude des activités de Boucherville dans le Haut-Canada à trois points de vue: la noblesse canadienne dans le commerce des fourrures; l'exploitation d'une entreprise de vente au détail dans les régions frontalières et les rapports que ce marchand laisse entrevoir entre les classes dirigeantes canadiennes et l'armée britannique dans les régions frontalières; le lien entre les activités commerciales et les affaires militaires. Ce fils de la petite noblesse canadienne et son Journal peuvent ainsi servir à illustrer la manière dont un cadet de famille noble, au début du XIX ${ }^{e}$ siècle, cherchait à s'établir financièrement ${ }^{6}$.

\section{II - FAMille, Relations et COMMERce Des FOURRURES}

\section{3-1804}

Au début de l'édition du Journal, parue en 1900, les responsables de la publication ont placé une longue histoire non signée de la famille de Boucherville. Quoique postérieur au Journal, ce complément généalogique s'avère tout à fait conforme à l'esprit de ces mémoires, étant donné l'importance que Thomas-Verchères de Boucherville accorda toujours à sa famille et au réseau de relations sociales et

\footnotetext{
' Il faut se rappeler que cette protestation de loyauté et de sacrifices, écrite en 1847 sans recourir à des notes, arrive quelques décennies après les événements, dans le cadre de requêtes où Boucherville fait valoir ses droits auprès des autorités britanniques.
} 
d'alliances politiques dans lequel elle évoluait. L'auteur ne néglige aucune occasion de mentionner les personnes qu'il a rencontrées, truffant son Journal du nom de gens en vue.

Au cœur de la haute société coloniale canadienne, formant une sorte de pacte aristocratique, se retrouvaient la composante loyaliste de la noblesse locale, des aristocrates britanniques établis plus ou moins durablement dans les colonies, mais aussi des militaires gradés de l'armée britannique issus de la gentry anglaise. Avec le temps s'ajoutèrent certains riches bourgeois. Le groupe comprenait même des aristocrates français venus sur le tard, comme le comte Joseph de Puisaye qui, au tournant du XIX ${ }^{e}$ siècle, tenta de s'établir dans le Haut-Canada à la tête d'un contingent de royalistes français ${ }^{7}$. Leur passage dans la colonie fut bref, à quelques exceptions près, par exemple le marchand Laurent Quetton de Saint-Georges ${ }^{8}$.

\section{A. LA NOBLESSE CANADIENNE}

Thomas-René-Verchères de Boucherville étant issu de la noblesse canadienne, il convient de situer ses activités ontariennes, non seulement dans le contexte de l'économie haut-canadienne, mais aussi dans celui de son héritage nobiliaire. On constate, en comparant plusieurs biographies de nobles canadiens, que le parcours de ce cadet de famille noble a suivi des sentiers bien battus par ses devanciers'.

\footnotetext{
${ }^{7} \mathrm{~N}$ [arcisse]-E[utrope] Dionne, Les Ecclésiastiques et les royalistes français réfugiés au Canada à l'époque de la révolution-1791-1802, Québec, s.é., 1905, xiv-447 p. Voir notamment les chapitres XI («L'émigration royaliste dans le Haut-Canada - 1798", pp. 127-140) et XII ("Les colonies de Windham et de Niagara et l'exode des royalistes $»$, pp. 141-165).

${ }^{8}$ Douglas McCalla, «Quetton St George, Laurent (baptisé Laurent Quet même si la famille s'appelait aussi Quetton [. .])", dans DBC Volume VI de 1821 à I835, [Québec], Presses de l'Université Laval, [c1987], pp. 687-690. Dans ce travail, nous désignerons ce personnage sous le nom de Laurent Quetton de Saint-Georges, même s'il signait parfois George au lieu de Georges et même si la particule «de» était parfois absente.

"Pour étudier les activités économiques de la «noblesse canadienne», le
} 
Comme l'a si succinctement écrit Chateaubriand, dans ses Mémoires d'outre-tombe: "L'aristocratie a trois âges successifs: l'âge des supériorités, l'âge des privilèges, l'âge des vanités: sortie du premier, elle dégénère dans le second et s'éteint dans le dernier." En France, la noblesse s'était constituée à l'époque du haut Moyen Âge, d'abord comme classe guerrière. Cette fonction militaire justifia longtemps ses privilèges sociaux et économiques. Mais les effectifs du "deuxième ordre", jusqu'alors renouvelés par filiation, se gonflèrent au temps de la Renaissance avec l'arrivée de la noblesse de robe. Car désormais, on pouvait aussi accéder à la noblesse par l'achat - et la conservation pendant un certain nombre de générations - de terres nobles ou de charges anoblissantes. D'autre part, certains candidats à l'anoblissement prenaient des raccourcis en se dotant de généalogies fictives. En 1666-1668, Louis XIV (1643-1715) ordonna la vérification des titres de toutes les familles nobles du royaume. De nombreuses usurpations furent exposées. De plus en plus, la noblesse de France se transformait en caste, jalouse de ses privilèges. Elle se referma encore plus au XVIII ${ }^{e}$ siècle, dans un mouvement de "réaction nobiliaire" qui se serait accentué à la veille de la Révolution française ${ }^{10}$.

Plusieurs grands aristocrates français sont venus en Nouvelle-France pour y occuper, plus ou moins longtemps, des postes de gouverneur (comme Louis de Buade, comte de Frontenac et de Palluau ou comme d'autres gouver-

Dictionnaire biographique du Canada fournit de bonnes pistes. Ses quatre premiers tomes couvrent la période avant 1800 , alignant de nombreux cas qui peuvent illustrer les comportements de ce groupe social: DBC Volume premier de l'an 1000 à 1700, [Québec], Presses de l'Université Laval, [c 1966], xxv-774 p.; $D B C$ Volume II de 1701 à 1740, [Québec], Presses de l'Université Laval, [c1969], xli-791 p.; DBC Volume III de 1741 à 1770, [Québec], Presses de l'Université Laval, [c1974], xlv-842 p.; DBC Volume IV de 1771 à 1800 , [Québec], Presses de l'Université Laval, [c1980], Ixiii-980 p.

${ }^{10}$ J.M., "Noblesse», dans Encyclopcedia Universalis (édition de 1980), volume 11, pp. 831-833. Pour le Canada, voir Charles E. Lart, "The Noblesse of Canada», dans Canadian Historical Review III, 1922, pp. 222-232. 
neurs généraux), pour y commander des armées ou des troupes (comme Louis-Joseph de Montcalm, marquis de Montcalm), pour y remplir des missions particulières. Les gouverneurs de la Nouvelle-France, qui représentaient les valeurs monarchiques et aristocratiques, furent tous des nobles, de même que tous les intendants (ceux qui n'étaient pas nobles le devinrent par la suite), de même que la plupart des officiers militaires, de même que tous les évêques et les dirigeants des communautés religieuses. Mais cette haute noblesse passa rapidement dans la colonie et ne se mêla pas à la noblesse locale.

La noblesse canadienne se recruta surtout parmi la petite noblesse rurale française, dont les fils servaient dans les troupes régulières envoyées en Amérique par la métropole. Par exemple, plusieurs officiers du régiment de CarignanSalières, appartenant à la noblesse, vinrent au Canada en 1665 et s'y fixèrent, comme Jacques Baby de Ranville, le grand-père de Jacques Dupéront Baby et donc l'arrièregrand-père de Jacques (James) Baby, membre du Conseil exécutif du Haut-Canada en 1792 et personnage en vue des environs de Détroit et de Sandwich au début du XIX ${ }^{\mathrm{e}}$ siècle. En 1667, l'intendant Jean Talon rapporta que la colonie ne comptait que quatre anciens nobles (le chevalier Jacques Le Neuf, sieur de la Poterie; Le Gardeur de Tilly; Le Gardeur de Repentigny; Charles-Joseph d'Ailleboust, seigneur des Muceaux) ${ }^{11}$.

Dans la société de la Nouvelle-France, la noblesse et le clergé occupaient le plus haut rang, une position privilégiée que des fonctionnaires et des marchands ambitieux aspiraient à partager. En fait, les anoblissements de roturiers ont beaucoup contribué à grossir les effectifs de la noblesse locale. Cet honneur couronnait parfois des exploits militaires, mais il reconnaissait aussi la réussite économique. Ainsi, l'acquisition de seigneuries ou l'enrichissement dans

${ }^{11}$ Lart, op. cit., pp. 227-228. 
la pêche ou la traite des fourrures préparaient parfois la voie à l'ascension sociale. Dès 1628 , le roi avait signé des lettres patentes anoblissant six familles reliées à la Compagnie de Caen, comprenant une douzaine de personnes. Quelques cas célèbres d'anoblissement peuvent illustrer ce cheminement, comme celui de Pierre Boucher, sieur de Grosbois (1622-1717), anobli en 1661, ceux de Jean Godefroy de Lintôt (1607/8-1681) et de Charles Le Moyne de Longueuil et de Châteauguay (1626-1685), anoblis en 1668, celui de Charles Aubert de la Chesnay (1632-1702), anobli en 1693, ou celui de Joseph-François Hertel de la Fresnière (1642-1722), anobli en $1717^{12}$. Chez Pierre Boucher, c'est le succès commercial qui a préparé son anoblissement; chez Aubert de la Chesnaye, ce sont ses grandes propriétés foncières; chez Charles Le Moyne, sa promotion s'explique par ses activités militaires et ses acquisitions de terres seigneuriales.

Plusieurs anoblis ont fondé de grandes familles et laissé une descendance nombreuse. Par exemple, Pierre Boucher est l'ancêtre de plusieurs lignées, les familles de Montarville, de Montbrun, de Grosbois, de Montizambert, de la Bruère, de Niverville, de la Perrière. Charles Le Moyne de Longueuil et sa femme Catherine Thierry eurent deux filles et douze fils, presque tous célèbres: Charles (baron de Longueuil), Jacques (sieur de Sainte-Hélène), Pierre (sieur d'lberville), Paul (sieur de Maricourt), François (sieur de Bienville), Joseph (sieur de Sérigny), François-Marie Le Moyne, Catherine Jeanne (elle épousa Pierre Payan de Noyon), Louis (sieur de Châteauguay), Marie-Anne (elle épousa le

\footnotetext{
${ }^{12}$ Voir Jean-Jacques Lefebvre, «Le Moyne de Longueuil et de Châteauguay, Charles", dans le DBC Volume premier de l'an 1000 à 1700, pp. 474-476; Yves F. Zoltvany, "Aubert de la Chesnaye, Charles», dans DBC Volume II de 1701 à 1740 , pp. 26-36; Raymond Douville, "Boucher, Pierre», dans DBC Volume II de 1701 à 1740, pp. 86-91; Raymond Douville, «Hertel de la Fresnière, Joseph-François", dans DBC Volume II de 1701 d̀ 1740, pp. 292-294; André Vachon, "Godefroy de Lintôt, Jean", dans le DBC Volume premier de l'an 1000 à 1700 , p. 350.
} 
sieur de La Chassaigne), Jean-Baptiste (sieur de Bienville), Gabriel (sieur d'Assigny) et Antoine (sieur de Châteauguay).

La Nouvelle-France, selon les intentions des autorités métropolitaines, devait reproduire en Amérique l'idéal métropolitain d'une société monarchique, hiérarchique et aristocratique reposant sur le régime seigneurial, c'està-dire sur la possession de la terre, comme en France. Mais les nobles devaient aussi gagner leur vie et ils participèrent à la course aux offices, demandant des postes dans l'armée, dans l'administration ou dans le système judiciaire. Enfin, ils recouraient souvent aux activités commerciales. Les membres de la noblesse, selon leur âge, exercèrent différentes activités. La plupart ont touché plusieurs secteurs au cours de leur vie active. En gros, la noblesse a été active principalement dans les quatre secteurs de la propriété foncière (par l'acquisition de fiefs et de seigneuries), de l'armée (par leur participation aux affaires militaires, dans les troupes de la marine, armée et milice), de l'administration (par l'exercice de certaines fonctions ou comme juges) et du commerce (dans les secteurs de la pêche, de la vente et de la traite des fourrures). Mais, au départ, la noblesse canadienne fut terrienne et militaire ${ }^{13}$.

Le lien entre la noblesse et la terre était primordial. La Nouvelle-France étant une société d'Ancien Régime basée sur l'agriculture, l'accès à la propriété foncière, tant pour le noble que pour le marchand, était à la fois une source de revenus et un outil de prestige et de promotion sociale. La possession de terres comptait puisque les rentes foncières

\footnotetext{
${ }^{13}$ Sur cet intérêt des nobles pour la terre et leur présence dans le système seigneurial, voir Fernand Ouellet, "Propriété seigneuriale et groupes sociaux dans la vallée du Saint-Laurent (1663-1840)", dans Mélanges d'histoire du Canada français offerts au professeur Marcel Trudel, Ottawa, Éditions de l'Université d'Ottawa, 1978, pp.183-213 (aussi publié dans la Revue de l'Université d'Ottawa, 1977, pp. 183-213); sur l'aspect militaire, voir Fernand Ouellet, "Officiers de milice et structure sociale au Québec (1660-1815)", dans Histoire sociale/Social History XII (numéro 23), mai 1979, pp. 37-63. Les prochaines pages doivent beaucoup à ces deux articles.
} 
donnaient des assises économiques à la noblesse, à mesure que le nombre de censitaires croissait. Ainsi, le gouvernement colonial distribua gratuitement aux deux ordres privilégiés de la société, le clergé et la noblesse, de nombreux fiefs et seigneuries. Au gré de leurs intérêts et du patronage officiel, les nobles et les marchands acquéraient des terres qu'ils exploitaient. Les nobles bénéficiaient des gratifications royales, des charges militaires et civiles, du patronage dans la traite des fourrures, mais c'est par la concession de seigneuries surtout qu'on entendait les y fixer, une attache qui assurerait leur intérêt à défendre la colonie.

La Nouvelle-France fut une société militariste où tous les hommes de 16 à 60 ans faisaient partie de la milice. De plus, l'armée française accueillit dans ses rangs beaucoup de fils de familles nobles canadiennes. La longue tradition guerrière de l'aristocratie française resta donc bien vivante et la vocation militaire se maintint comme caractéristique fondamentale de la noblesse canadienne. La colonie était constamment en guerre, contre les Amérindiens ou contre les Anglais, créant une insécurité qui favorisa cette classe militaire. Elle fut récompensée par la distribution de seigneuries et par des permissions de participer au commerce des fourrures. Dans la colonie, ces mêmes familles obtenaient une grande partie des charges militaires, comme les fonctions de gouverneur général ou gouverneurs locaux, de lieutenants du roi et autres. La plupart des nobles, sauf les membres du clergé, ont fait une période de service militaire, dans la marine ou dans les armées de terre.

Un troisième domaine d'intervention de la noblesse concernait leur participation à diverses charges civiles, des fonctions très convoitées, autant par les militaires que par les nobles de robe. Cette activité ouvrait le volet politique et permettait à la noblesse d'agir dans le domaine du pouvoir civil. Ils s'agit de places à combler comme celles du Conseil souverain, où sont nommés des conseillers et des 
officiers, ou des fonctions judiciaires, dans la justice royale ou seigneuriale.

Le quatrième grand rôle de la noblesse canadienne fut commercial. En France, la noblesse ne pouvait pas, en principe, faire le commerce (excepté le commerce international) sans déroger, car elle devait vivre noblement. En France comme en Nouvelle-France, les anoblissements se faisaient en premier lieu à partir de la bourgeoisie. Dans les colonies, les nobles participaient sans déchéance au commerce. Plusieurs obtenaient des congés de traite, comme les familles Damours et Gaultier de La Vérendrye. Certains anoblis, qui avaient réussi en affaires avant leur accession à la noblesse, continuèrent de s'occuper de leurs intérêts économiques, des pratiques séculaires qui éclairent les comportements et la carrière de Verchères de Boucherville au début du XIX ${ }^{e}$ siècle. Fernand Ouellet nuance toutefois l'importance de cette activité économique: «Il n'y a pas de doute que la grande majorité des nobles est impliquée dans les activités commerciales, en particulier dans la traite et les pêcheries. Mais tout cela ne permet pas d'affirmer sans beaucoup de nuances le caractère commercial de la noblesse ${ }^{14}$."

Deux exemples illustreront la participation de la noblesse canadienne au commerce: les La Vérendrye et les Baby.

René Gaultier de Varennes (v. 1635-1689), officier dans le régiment de Carignan-Salières, reçut en 1681, en fief anoblissant, la seigneurie de La Vérendrye. Ce gendre de Pierre Boucher de Boucherville fut gouverneur de TroisRivières, poste qu'il utilisa pour faire la traite. Son fils, Pierre Gaultier de Varennes et de La Vérendrye (16851749) fut aussi officier, mais il fut surtout trafiquant de fourrures et explorateur à l'ouest du lac Supérieur où il érigea une chaîne de forts jusqu'aux Rocheuses (dont le

${ }^{14}$ Ouellet, «Propriété seigneuriale. .», p. 188. 
fort Saint-Pierre au lac La Pluie en 1731 et le fort SaintCharles au lac des Bois en 1732). La Vérendrye effectua ces activités entre 1731 et 1749 avec l'aide de ses quatre fils.

Il y a aussi le cas intéressant des Baby. Le premier de la famille au Canada, Jacques Baby de Ranville, arrivé en 1665 avec le régiment de Carignan-Salières, avait été marchand de campagne, mais son fils Raymond participa au commerce des fourrures dans l'Ouest, de même que son petit-fils Jacques Dupéront Baby (1731-1789) qui continua "la tradition familiale, si révélatrice de la mentalité des seigneurs de l'époque, de se réclamer de la noblesse et de participer activement à la traite des fourrures, tout en résidant à Montréal ${ }^{15} »$. Jacques Dupéront Baby se rendit dans l'Ouest au début des années 1750 , où il devint un important marchand de fourrures. Il partit après la Conquête, mais revint vite au Canada où il s'associa à son frère François, à Montréal, puis retourna dans l'Ouest en 1762. Il fut nommé agent du département des Affaires indiennes. Il s'installa avec sa femme à Détroit où il prospéra, acheta beaucoup de terres, fit la traite des fourrures, acheta des terres à bois, devint juge de paix en 1784 et laissa une grosse fortune. Deux de ses fils, François (1768-1852) et Jacques (1763-1833), firent aussi de belles carrières dans la région du Détroit, mais leur famille était très nombreuse (Jacques Dupéront Baby et son épouse Suzanne Réaume eurent vingt-deux enfants, dont onze parvinrent à l'âge adulte).

On est en présence d'un groupe social qui, en 1663 (selon les chiffres de Marcel Trudel), possédait plus de $60 \%$ du sol, jouait un rôle militaire prédominant et participait de multiples façons au commerce des pelleteries. Pourtant, cet historien de la Nouvelle-France n'a vu dans la noblesse canadienne qu'un "groupe disparate d'individus qui sont nobles», ne formant pas une classe sociale ${ }^{15}$ Dale Miquelon, «Baby, dit Dupéront [. .], Jacques», dans DBC IV de 1771 à 1800 , p. 42. 
homogène, encore moins un ordre privilégié16. Il n'a existé dans la colonie ni charge anoblissante, ni achat de lettre de noblesse. Ici comme en France, on devenait le plus souvent noble par la naissance ou par l'octroi de lettres de noblesse. Quant à la propriété d'une seigneurie, elle ne conférait pas la noblesse, encore qu'elle donnât du prestige. Modeste, le noble canadien se confondait avec le roturier «par sa mentalité, par ses préoccupations, par sa participation au commerce des fourrures, par son train de vie». Pauvre, cette noblesse canadienne était «essentiellement besogneuse ", son seul privilège étant le droit de porter l'épée et le titre d'écuyer. Les nouveaux nobles enjolivaient souvent leur nom d'un deuxième patronyme et de la particule de placée devant leur nouveau nom (Boucher de Boucherville). La noblesse canadienne ne comprenait qu'une vingtaine de familles au XVII ${ }^{\mathrm{e}}$ siècle ${ }^{17}$.

Le rôle militaire de la noblesse canadienne fut jusqu'à un certain point compromis par la Conquête de $1760^{18}$. Comment survivre sans le patronage de l'État? Un inventaire de la noblesse compilé en 1767 par Guy Carleton énuméra 228 nobles (126 résidant au pays, 102 ayant quitté après 1760$)^{19}$. Dans un premier temps, les autorités britanniques voulurent détruire l'ordre ancien. En 1763, elles décidèrent d'appliquer les lois anglaises et d'abolir la Coutume de Paris, d'imposer le serment du test pour bannir les catholiques de toute fonction civile ou militaire, de

\footnotetext{
${ }^{16}$ Pour ce débat, voir Marcel Trudel, La Population du Canada en 1663, Montréal, Fides, «Fleur de lys». [c1973], xI-368 p., et le compte rendu de Fernand Ouellet sur trois ouvrages de Trudel (La Population du Canada en I663, Le Terrier du Saint-Laurent en 1663 et Les Débuts du régime seigneurial), dans Histoire sociale/Social History VIII (numéro16), novembre 1975 , pp. 371-372.

${ }^{17}$ Marcel Trudel, Initiation à la Nouvelle-France, Montréal, Éditions HRW, [c1968], pp. 152-153.

${ }^{18}$ Voir, à ce sujet, Fernand Ouellet, «Officiers de milice. .», pp. 37-63.

${ }^{19}$ Cet inventaire est reproduit par Fernand Ouellet, "La "noblesse canadienne" en 1767: un inventaire", dans Histoire sociale/Social History I, avril 1968, pp. 129-137.
} 
fermer l'Ouest au commerce des fourrures, d'abolir le régime seigneurial et de supprimer la dîme.

Les nobles restés au pays traversèrent, de 1763 à 1774, une grande période d'incertitude: «Réduite dans ses effectifs, coupée du commerce des pelleteries, exclue des cadres de l'armée britannique, la noblesse francophone devient une noblesse terrienne conservant néanmoins l'espoir de recouvrer son ancien statut tant dans l'armée que dans la traite et l'administration ${ }^{20}$.» Les militaires rentrant en France vendaient leurs seigneuries aux aristocrates et aux marchands anglais. Mais les mesures de 1763 furent mal ou peu mises en œuvre: la traite reprit, on permit la consécration d'un évêque catholique, on chercha à temporiser, avant de décider de conserver la société seigneuriale canadienne. L'Acte de Québec (1774) sauva la noblesse en restaurant le droit civil français, y compris le régime seigneurial et la dîme, et en reconnaissant aux catholiques le droit de pratiquer leur religion. C'était une grande victoire pour la noblesse et le clergé. Cette mesure de réconciliation les rallia à la cause britannique. Lors de l'invasion américaine en 1775 , les nobles se trouvèrent nombreux à la tête de milices canadiennes (officiellement rétablies en 1777) ${ }^{21}$. Désormais, la noblesse s'intéressa beaucoup aux milices, ce qui signifiait l'intégration des nobles canadiens dans l'armée régulière britannique.

Sous le Régime britannique, les gouverneurs et les militaires qui les entouraient sortaient des rangs de la noblesse britannique ou de la gentry. Plusieurs acquirent dans la colonie des seigneuries. Les mâles seuls pouvaient transmettre la noblesse, mais certains négociants britanniques tentèrent d'y accéder par le mariage à des femmes issues de familles nobles. De telles tentatives montrent au moins la persistance des valeurs monarchiques et aristocratiques.

${ }^{20}$ Ouellet, «Propriété seigneuriale. .", p. 184.

${ }^{21}$ Benjamin Sulte, Histoire de la milice canadienne-française, 1760-1897, Montréal, Desbarats, 1897, 147 p. 
De leur côté, les nobles canadiens entrèrent dans les conseils, on créa pour eux un régiment, ils se mirent bien en vue lors de la Guerre de 1812.

Les habitudes commerciales de la noblesse canadienne avaient donc préparé les activités économiques de ThomasRené-Verchères de Boucherville dans le Haut-Canada.

\section{B. LA FAMILLE DE BOUCHERVILLE}

Les Boucher de Boucherville descendaient du patriarche Pierre Boucher (1622-1717), arrivé au Canada à l'âge de treize ans en $1635^{22}$. Éventuellement, il devint seigneur de Boucherville et fonda une famille nombreuse. Personnage en vue de la colonie, il occupa diverses fonctions. Interprète et soldat, mais remplissant aussi des fonctions judiciaires et politiques, il fut anobli en 1661 , avec de nouvelles lettres en 1707. Son fils Pierre Boucher (1653-1740) mit la seigneurie familiale en valeur, favorisant la colonisation, sans négliger de guerroyer contre l'Iroquois. On trouve, à la troisième génération, François-Pierre de Boucherville (1689-1767), un militaire qui fut capitaine d'infanterie et chevalier de Saint-Louis ${ }^{23}$. Il est intéressant de souligner que ce grand-père de Thomas-Verchères Boucher de Boucherville fut commandant au fort Niagara de 1736 à 1740. Son fils René-Amable Boucher de Boucherville (17351812), le père de Thomas-Verchères, était même né dans les Pays d'en haut, ayant vu le jour au fort Frontenac (aujourd'hui Kingston), sur les bords du lac Ontario ${ }^{24}$. Plus tard, il suivit son père dans la carrière des armes, servit avec les troupes françaises de la marine et fut blessé à la

${ }_{22}^{2}$ Raymond Douville, «Boucher, Pierre», dans DBC Volume II de 1701 à 1740 , [Québec], Presses de l'Université Laval, [c1969], pp. 86-91.

${ }^{23}$ En collaboration, «Boucher de Boucherville, Pierre (baptisé François-Pierre)», dans DBC Volume III de 1741 à 1770, [Québec], Presses de l'Université Laval, [c1974], pp. 85-86.

${ }^{24}$ Céline Cyr, «Boucher de Boucherville, René-Amable», dans DBC Volume V de 1801 à 1820, [Québec], Presses de l'Université Laval, [c1983], pp. 105-106. 
bataille des Plaines d'Abraham en 1759. Capturé, il rentra en France après la défaite de 1760 , mais revint au Canada en 1763. Quatre ans plus tard, René-Amable Boucher hérita du quart de la seigneurie de son père. Après l'Acte de Québec, comme plusieurs de ses semblables dans la noblesse canadienne, il se rallia à la Couronne britannique et combattit en 1775-1776, lors de l'invasion américaine, aux côtés des soldats britanniques. En récompense de son loyalisme, il fut nommé grand voyer du district de Montréal en 1785 , fonction qu'il n'abandonna qu'en 1806 , au profit de son gendre. Après 1790, il détint le rang de colonel de milice. Il entra en 1807 au Conseil législatif, charge qu'il conserva jusqu'à sa mort en 1812 .

Cette quatrième génération, représentée par Pierre-RenéAmable Boucher et son épouse Madeleine Raimbault, comptait onze enfants, mais plusieurs moururent en bas âge. L'aînée, Charlotte, épousa Louis-René Chaussegros de Léry (1762-1832), celui qui succéda en 1806 à son beau-père comme grand voyer du district de Montréal. Lui aussi fut militaire, fonctionnaire, juge de paix, enfin membre, à partir de 1818, du Conseil législatif ${ }^{25}$. Pierre-Amable épousa Marguerite-Émilie Sabrevois de Bleury, tandis que CharlesMarie devint religieux. Surtout, le dixième des onze enfants, appelé Thomas-René Boucher (1784-1857), est l'auteur du Journal.

Cela faisait beaucoup de monde à établir pour un seigneur aux ressources limitées. Mais la famille pouvait compter sur ses nombreuses relations. C'est ainsi que René-Amable Boucher de Boucherville aborda le sujet de l'avenir de son jeune fils, Thomas, avec l'illustre et riche marchand de fourrure Alexander Mackenzie, explorateur, en 1789 , du fleuve qui porte son nom et découvreur, en 1793, d'une route à travers les Rocheuses jusqu'à l'océan

\footnotetext{
${ }^{25}$ Roch Legault, "Chaussegros de Léry, Louis-René », dans DBC Volume VI de 1821 à 1835 , pp. 145-146.
} 
Pacifique ${ }^{26}$. Cet influent marchand, récemment devenu le principal bourgeois de la Nouvelle Compagnie du NordOuest, embaucha le jeune Thomas Boucher comme commis en 1803.

Thomas-René Boucher naquit à Boucherville, province de Québec, le 21 décembre $1784^{27}$. Après des études au collège sulpicien Saint-Raphaël de Montréal, entre 1792 et 1799, il passa quatre années à Boucherville, dans ce qu'il appela plus tard, sans en dire la nature, de "folles équipées». En 1803, à l'âge de dix-huit ans, il entrait donc au service de la Nouvelle Compagnie du Nord-Ouest. Après une année difficile dans le Nord-Ouest, Thomas-Verchères de Boucherville rentra chez lui, mais fit subséquemment plusieurs longs séjours dans le Haut-Canada, notamment à York (Toronto) et à Amherstburg. Après un échec commercial en 1816, il renonça définitivement au commerce de détail. Il épousa en 1819 Clotilde-Joséphine Proulx, fille d'un bourgeois en vue de Montréal, Louis-Basile Proulx. Ils eurent cinq enfants. En 1829, Thomas-Verchères de Boucherville devint par héritage coseigneur de Verchères et de Boucherville. Il fut aussi nommé major de milice et juge de paix. Il mourut à Boucherville le 13 décembre 1857, une décennie après avoir rédigé son Journal.

Les Boucherville soignèrent toujours leurs relations avec les autorités britanniques. Aux plans social et politique, ils firent partie du groupe des privilégiés hostiles aux réformes annoncées par l'Acte constitutionnel de 1791 et opposés aux revendications politiques de la nouvelle bourgeoisie professionnelle appuyant le parti réformiste, connu au BasCanada sous la désignation de parti canadien, plus tard patriote. La noblesse canadienne formait alors un élément essentiel de la structure sociale de la colonie. Toutefois, et malgré son fort sentiment de constituer une classe sociale

\footnotetext{
${ }^{26}$ W. Kaye Lamb. «Mackenzie, sir Alexander», dans DBC Volume V de 1801 à 1820, pp. 591-598.

${ }^{27}$ René Dionne, op. cit., pp. 427-429; Frederick H. Armstrong, op. cit., pp. 111-112.
} 
et même l'élite de la société, ce groupe était néanmoins en perte de pouvoir. Les intérêts de la noblesse, opposée aux réformes libérales, rejoignaient souvent ceux des militaires britanniques et des grands marchands, auxquels ils étaient liés par des alliances matrimoniales et par des intérêts

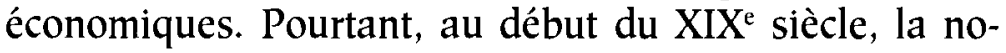
blesse canadienne était une classe en déclin ${ }^{28}$.

Il se développa donc une solidarité entre les groupes sociaux dominants et unis dans une cause commune rattachée à l'empire britannique. Dans son étude des marchandsnégociants de Québec, qui font partie de la grande bourgeoisie du Bas-Canada, George Bervin a montré à quel point l'élite marchande, surtout l'anglo-écossaise, se sentait solidaire de l'empire britannique ${ }^{29}$. Une conclusion dans le même sens se trouve chez Fernand Ouellet: «L'appartenance à l'empire n'est pas un vain mot. Elle signifie d'abord une insertion dans un ensemble de structures qui influent directement sur l'activité coloniale ${ }^{30}$.» Les opinions probritanniques de Verchères de Boucherville avaient leur raison d'être et s'affichaient au grand jour. Dans le Haut-Canada, les grands marchands, alliés aux bureaucrates britanniques, formaient aussi une élite sociale et économique.

Cette participation des élites aux affaires militaires procurait aux marchands-négociants, qui occupaient l'échelon supérieur de la classe bourgeoise, un accès privilégié tant à l'administration civile (certains étaient même inscrits sur la

\footnotetext{
${ }^{28}$ Sur la noblesse canadienne: Lorraine Gadoury, La Noblesse de NouvelleFrance. Familles et alliances, [Montréal, "Cahiers du Québec - Histoire», c1992], [16]-208 p. Pour l'étude de quelques familles nobles du voisinage (Sorel, Saint-Ours), voir Allan Greer, Habitants, marchands et seigneurs. La société rurale du bas Richelieu 1740-1840, traduit de l'anglais par Jude Des Chênes, [Québec], Septentrion, [c2000, original anglais 1985], 357 p.

${ }^{29}$ George Bervin, Québec au XIX siècle. L'activité économique des grands marchands, [Québec], Septentrion, [c1991], p. 18.

${ }^{30}$ Fernand Ouellet, Histoire économique et sociale du Québec 1760-1850. Structures et conjoncture, Montréal, Fides, [c1966], p. 27.
} 
liste civile du Bas-Canada) que militaire. Souvent, ils remplissaient même de hautes fonctions dans l'appareil militaire colonial et pouvaient done faire mieux valoir leurs préoccupations auprès des autorités. Il devint alors plus facile pour eux de profiter de certaines activités rémunératrices, comme le ravitaillement de l'armée. Ils furent «les premiers bénéficiaires des importants contrats militaires pour l'approvisionnement ${ }^{31}{ }^{\prime}$.

C'est au monde des seigneurs que Verchères de Boucherville retourna inéluctablement en 1816 , après une jeunesse passée à brasser, tantôt avec succès, tantôt vainement, des affaires commerciales menées entre 1803 et 1816 . Il revenait à la terre et à des rôles qui avaient été la cause de sa noblesse. Ces activités commerciales représentent une parenthèse marchande dans la vie d'un homme appartenant au monde seigneurial.

\section{Verchères de BoucherVILLE dans Le NoRd-OUeST}

Depuis le début du XVII e siècle, en Nouvelle-France, le mode de vie auquel aspirait cette noblesse canadienne l'avait conduite vers l'activité économique la plus lucrative de la colonie, c'est-à-dire le commerce des pelleteries. Les seigneurs et les militaires avaient souvent cherché à faire, ou à refaire, leur fortune personnelle dans ce trafic qui pouvait rapporter gros, plus que l'exploitation des terres. Mais l'agriculture et le commerce des fourrures ne furent pas forcément des activités incompatibles, loin de là, leur complémentarité se manifestant dès l'époque de la NouvelleFrance. Fernand Ouellet parle à ce sujet de «dualité économique $^{32}$ ». En fait, la noblesse continua longtemps de s'appuyer sur le commerce des fourrures pour supporter ses ambitions terriennes (comme commandants des postes

${ }^{31}$ George Bervin, op. cit., p. 46.

${ }^{32}$ Voir Fernand Ouellet, «Dualité économique et changement technologique au Québec (1760-1790)», dans Histoire sociale / Social History IX (numéro 18), novembre-décembre 1976, pp. 256-296. 
et comme dépositaires de congés de traite qu'ils exploitaient eux-mêmes ou qu'ils faisaient exploiter par d'autres).

Plusieurs membres de la noblesse canadienne s'adonnèrent à cette double activité, sans jamais perdre de vue que leur objectif restait, finalement, de s'établir sur des terres et de vivre "noblement" en aristocrates richement dotés au point de vue foncier. Verchères de Boucherville peut justement illustrer ce cheminement, puisque, né dans la noblesse, il ne devint plus tard seigneur qu'après avoir été marchand. La noblesse fut en quelque sorte amenée à pratiquer le commerce des fourrures, en complémentarité à l'agriculture, pour soutenir le style de vie auquel elle aspirait:

Cet attrait pour le genre de vie noble a deux conséquences importantes. D'abord il contribue, même si la terre n'a pas une importance économique considérable, à valoriser au maximum la propriété foncière [. . ]. Pour étonnant que cela paraisse, elle [l'attirance pour le train de vie noble] aboutit à mettre en valeur le rôle indispensable du commerce des fourrures, dont on déplore les méfaits, mais dont on accepte finalement toutes les servitudes. Il est évident que l'emprise des «Pays d'EnHaut" ne tient pas seulement à ces considérations. Le goût de l'aventure, un fort besoin de libération à l'égard des contraintes du milieu expliquent autant que l'appât du gain cet incessant vaet-vient entre les basses terres du fleuve et l'[O]uest. Il n'en reste pas moins que le désir de promotion sociale, le besoin de prestige et la nécessité de maintenir son rang impliquaient une réconciliation entre la société nobiliaire et le monde des fourrures ${ }^{33}$.

Ainsi, le départ du jeune Thomas-Verchères de Boucherville vers l'Ouest, en 1803, n'avait rien de surprenant.

Au début du XIX ${ }^{e}$ siècle, le trafic des fourrures, centré sur Montréal, brûlait de l'éclat de ses derniers feux. En 1770 , encore, la fourrure représentait $76 \%$ des exportations à Québec, puis $51,4 \%$ en 1788 et seulement $9,2 \%$ en $1810^{34}$. Le commerce des pelleteries déclinait. La région

\footnotetext{
${ }^{33}$ Fernand Ouellet, Histoire économique et sociale..., p. 561.

${ }^{34}$ Ibid., p. 37.
} 
au-delà du lac Supérieur faisait encore partie de l'aire commerciale centrée sur le bassin des Grands Lacs et contrôlée par les marchands de Montréal, certes, mais il fallait parcourir des distances de plus en plus grandes et concurrencer la Compagnie de la baie d'Hudson qui, elle, pouvait s'approvisionner plus directement en passant par le nord. Alexander Mackenzie envisageait déjà la fusion des entreprises de Montréal avec la Compagnie de la baie d'Hudson, une idée qui lui fit des ennemis, mais une consolidation qui se réalisa effectivement en 1821. En attendant, le commerce des fourrures continuait de survivre.

Toutefois, pour le jeune Thomas Boucher, le choc du voyage dans l'Ouest fut rude. À peine parti, il regretta sa décision de s'engager pour une durée de sept ans. Souffrant de froid, d'ennui et de maladie, le commis s'apitoya vite sur son triste sort. L'inconfort était physique, mais aussi social: «Moi, jeune homme de dix-huit ans, n'ayant jamais laissé la maison paternelle pour aucun long voyage, ne connaissant aucunement le jargon presque barbare des voyageurs, leurs coutumes, leurs manières de vivre [. . ]" (JVB 2). Ainsi, dès le départ, Thomas Boucher se démarquait socialement des simples voyageurs qui faisaient de toute évidence partie d'une autre classe sociale. Ni le passage du temps, ni le travail ne guérirent l'angoisse du jeune commis dont les craintes grandissaient. Bien que rédigé plusieurs décennies après les événements rapportés, le Journal rappelle les pensées troubles du jeune homme qui commençait «à réfléchir sur la folie qui [lui] était venue de partir pour un tel voyage [. .] sans espoir de venir sécher les larmes de [s]a pauvre mère que [s]on départ inconsidéré avait fait couler" (IVB 2).

Le récit du Journal est intéressant pour ce qu'il nous apprend de la vie quotidienne d'un commis travaillant dans l'Ouest ${ }^{35}$. Quittant Montréal, il lui fallut d'abord se

${ }^{35}$ Pour une description de la vie des voyageurs, voir Grace Lee Nute, The Voyageur, Saint-Paul (Minnesota), Minnesota Historical Society, [c1931], x-289 p. 
rendre à Grand-Portage, à l'extrémité occidentale du lac Supérieur. Le jeune aventurier, n'emportant pour tout bagage que sa cassette et ses deux couvertures de lit (JVB 7), partit de Lachine en compagnie d'un groupe de commis, dont il consigna les noms: Vienne, Curotte, McMullin, Gordon et Cameron. Le convoi de canots emprunta la route des voyageurs, remontant l'Outaouais, traversant le lac Nipissing et descendant la rivière des Français, pour atteindre ensuite Sault-Sainte-Marie, à l'entrée du lac Supérieur. Après sept jours d'attente, l'équipe monta à bord du schooner Perceverança, mais la goélette fut secouée sur le lac Supérieur par une grosse tempête qui fit craindre le naufrage. Les hommes furent sauvés, mais on vit périr «deux superbes vaches que nous avions sur le pont, une perte des plus irréparables pour nous» (JVB 67). On atteignit enfin le mythique Grand-Portage dont Boucherville avait «si souvent entendu parler dans [s]on enfance par les voyageurs de [s]on village" (JVB 7).

Thomas Boucher donne de ce poste de traite la description suivante:

Ce Fort était magnifiquement situé sur une belle côte, d'où l'on y [sic] jouissait d'un point de vue superbe. Il avait été construit par la société du Nord-Ouest, et consistait en piquets de cèdre assez élevés et de bastions aux quatre coins. Dans l'enceinte, il se trouvait plusieurs belles bâtisses pour l'usage des membres de la société seulement, surmontées d'un grand mât sur lequel, les dimanches et les jours d'arrivée des principaux Bourgeois, on hissait un beau et grand pavillon (JVB 8).

Ce beau site, cependant, était sur le point d'être abandonné au profit du fort William (Thunder-Bay aujourd'hui), au nord-est, emplacement plus sûr parce que plus éloigné de la frontière américaine. À Grand-Portage, Thomas Boucher fut reçu «avec grande politesse» par un dénommé Nolin «qui déjà avait entendu parler de [lui] par son fils parti l'année précédente lui aussi pour les pays d'en haut" (JVB 4). Entre-temps, le commis logeait sous la tente et 
avait la responsabilité de surveiller un hangar «où étaient déposées les boissons" (JVB 8). L'ennui du jeune homme persista, même "[a]près avoir réfléchi un peu sur [s]on triste sort et avoir versé à la dérobé[e], une larme au sujet de [s]on éloignement de [s]es chers parents» (JVB 7).

Puis arriva l'heure du départ pour le fort Dauphin (voir la CARTE I). On monta dans des canots du Nord, plus légers. L'embarcation de Boucher avait pour guide un dénommé Ducharme, alors qu'un certain Laporte tenait le rôle de gouvernail. En route, un accident se produisit. Un baril tomba sur la main du nouveau commis qui perdit une partie de son index. Il soigna sa blessure comme il put, ayant heureusement apporté une fiole de baume de rigat, dont il appliqua quelques gouttes, «ce qui [l]e guérit en peu de jours" (JVB 9). Au lac à la Pluie, Boucher rencontra «avec plaisir [un] nommé Lacombe qui y était commis, un cousin des familles Lacombe de [s]a paroisse natale» (JVB 9). On attendit huit jours les directives des supérieurs. Quand elles arrivèrent, les employés remplirent les canots «de provisions, suif, blé-d'inde, etc.» et partirent (JVB 9). En quelques jours, on parvint à la "rivière Ouinipegue». Le Journal nous apprend alors que Thomas Boucher avait apparemment amené son chien Osmar (JVB 14). Toujours soucieux de ses relations, l'auteur dit qu'il a rencontré alors un groupe dirigé par un dénommé Jacob: "J'appris qu'il demeurait au Bas-Canada et qu'il avait une sœur de mariée à Boucherville» (JVB 11). L'équipe traversa le «lac Ouinipegue», puis le lac Manitoba en accélérant la vitesse des canots par le déploiement de voiles. En quelques jours, on atteignit la rivière où se trouvait le fort Dauphin. Boucherville y rencontra Thomas McMurray, responsable du poste, et il eut aussi le plaisir de renouer connaissance avec «le jeune Nolin».

Le Journal contient ensuite un récit des difficultés à surmonter: l'isolement, les rudes conditions de vie, un mal de jambe continu. Verchères de Boucherville se familiarisa 
avec les lieux, achetant des fourrures, rencontrant les autochtones qui y vivaient. Il souffrait souvent de la fièvre et de "ce vilain mal de jambe qui [l]'avait fait tant souffrir» (JVB 17). L'ennui aussi le rongeait: "En outre, l'idée de la maison paternelle, "home", se mit à me hanter d'une manière peu propre à me réjouir et r[é]conforter" (JVB 18). Dès le mois de décembre 1803 , le jeune homme désespérait et "souffrai[t] le martyre, quoi donc" (JVB 18). L'hiver 1803-1804 lui parut bien long. L'ennui le tourmentait. Il passa un mois seul avec les Amérindiens, négocia l'achat de fourrures et tendit près du fort quelques pièges en compagnie d'un dénommé Lafleur.

En février 1804, son supérieur McMurray envoya Verchères de Boucherville et cinq hommes (l'interprète Clermont, Boisvert, Goulet, Lauzon et Allaire) passer le reste de l'hiver à la montagne aux Canards, au nord-ouest. Il partit avec des chiens et un toboggan (JVB 23) et passa février et une partie de mars 1804 auprès des Amérindiens. Il fut dérouté par la langue des autochtones, qu'il ne comprenait pas, et par leurs pratiques religieuses, notamment la cabane de jonglerie ("hideuse cérémonie», écrit-il). S'étant moqué de ces pratiques superstitieuses, Boucher dut partir par crainte de représailles de la part des Amérindiens et revenir au fort Dauphin. En route, il faillit se noyer. Il souffrait d'une forte fièvre, de maux de jambe et de son "détestable état de santé». Revenu de son expédition, il informa McMurray de son intention de rentrer au BasCanada ("car je n'en pouvais plus», précisa-t-il, JVB 30).

Boucherville quitta le service de la société en mai 1804 , muni d'une lettre de McMurray pour expliquer au père du jeune commis pourquoi son fils revenait après une année seulement. La décision de revenir à Boucherville était prise: «Enfin, le bien-fondé de la cause qui m'avait fait demander la remise de mon engagement, joint aux violents désirs d'embrasser mon père et ma mère et de revoir toute ma famille, et aussi de me procurer une occupation moins 
dangereuse pour ma santé, l'emportèrent et je m'arrête définitivement à ma première détermination" (JVB, 3233). McMurray mit à la disposition de Verchères de Boucherville "six bons hommes", des volontaires non identifiés dont le contrat prenait fin et qui se rendaient à Grand-Portage pour y rencontrer les hyvernants. En quatre jours, le groupe atteignit le «lac Ouinipegue", mais il était déjà à court de provisions. En route, il rencontra un des bourgeois de la Compagnie, Pierre Rastel de Rocheblave: «De suite, écrit l'auteur du Journal, j'allai le saluer. Cet excellent monsieur me reçut avec politesse en apprenant mon nom, car il connaissait fort bien mon père." Il donna un peu de nourriture à ces voyageurs presque démunis. Ils arrivèrent à Grand-Portage fin juin 1804, puis attendirent quelques jours la goélette qui permit de traverser le lac Supérieur, en compagnie du bourgeois Thomas Thain, neveu de l'important homme d'affaires montréalais John Richardson (v. 1754-1831), et d'une douzaine de voyageurs $^{36}$. Le trajet prit douze jours. Boucherville accepta l'invitation de Thain de l'accompagner à Michillimakinac: "Je connaissais plusieurs des familles qui l'habitaient, et j'eus le plaisir d'apprendre que mon frère Pierre de Boucherville, y était arrivé depuis peu, se dirigeant du côté des Illinois" (JVB 36). Enfin, en août, Thain et sa suite partirent pour Montréal où ils arrivèrent douze jours plus tard. Thain remit à Boucherville un peu d'argent pour lui permettre de se «présenter décemment dans [s]a famille, à Boucherville» (JVB 36).

Le jeune homme refit sa toilette, acheta un costume («une paire de pantalons de corderoi couleur olive, une veste rouge et un gilet de même étoffe que le pantalon; mon argent y avait passé "). Ses deux parents eurent des réactions différentes en le voyant de retour: «Ma mère me fit grande joie, mais mon père me semblait très grave.» Par-dessus tout, le

${ }^{36}$ Gratien Allaire, "Thain, Thomas", dans, DBC Volume VI de 1821 à 1835, pp. 843-845. 
jeune commis semblait craindre la réaction de son père: "Je n'aurais jamais osé me présenter devant mon digne père sans un tel certificat, car il ne badinait nullement avec ce qu'il nommait le devoir" (JVB 31). L'ancien commis montra alors le certificat qui "produisit un effet merveilleux». La lettre de McMurray à René-Amable de Boucherville, reproduite au long dans le Journal, est datée du 24 mai 1804, au fort Dauphin. Le responsable du fort exonérait le jeune homme "de toute calomnie» et précisait: «Je puis vous assurer que ce n'est que la maladie qu'il a dans les jambes et de quoi il se plaint toujours dans les grandes marches, et non par aucune mauvaise conduite ou de mal comportement envers ou contre les intérêts de la Compagnie qu'il nous a quitté[s]». Après avoir montré le document à son père, écrit Boucherville, «je fus alors traité par le chef de famille avec toute sa bonté ordinaire" (JVB 38).

Ainsi prenait fin le séjour de Thomas-Verchères Boucher de Boucherville dans le Nord-Ouest ontarien et l'Ouest (Manitoba). Mais ce qu'il avait appris sur le trafic des fourrures lui servirait encore dans la décennie suivante, dans le sud-ouest du Haut-Canada.

\section{III - BOUCHERVILE ET LE COMMERCE DE DÉtAIL 1804-1812}

En octobre 1804, Thomas-Verchères de Boucherville fit la connaissance de celui qui allait affecter profondément la prochaine décennie de sa vie. Le jeune commis, récemment revenu du Nord-Ouest, fit alors la rencontre de Laurent Quetton de Saint-Georges (1771-182 1), un aristocrate français engagé dans le commerce à York (Toronto), dans le Haut-Canada, peut-être le marchand le plus considérable de cette ville.
A. ÉCONOMIE ET COMMERCE DE DÉTAIL
À cette époque, l'économie laurentienne, centrée sur la vallée du fleuve Saint-Laurent, englobait le Bas et le Haut- 
Canada dans des frontières poreuses, les deux participant en fait à une économie nord-américaine ouverte à la circulation des personnes et des biens.

Cette économie coloniale entretenait des relations commerciales complexes avec la métropole britannique. En échange de matières premières telles le blé, la potasse et le bois, la colonie recevait divers produits manufacturés ou exotiques (le thé, le sucre, les tissus et divers objets de mercerie et de quincaillerie, aussi certaines denrées alimentaires). L'économie ontarienne se composait done de deux éléments: la production pour les marchés locaux, comprenant une grande gamme de produits de consommation, et la production pour l'exportation ${ }^{37}$. Au début du XIX ${ }^{e}$ siècle, comme l'a montré l'historien Douglas McCalla, l'économie du Haut-Canada se transformait ${ }^{38}$. Le mouvement général de l'économie connut les fluctuations suivantes: hausse (1793-1800), baisse (1800-1808) et hausse (1808-1816) ${ }^{39}$. Les activités commerciales de Verchères de Boucherville auraient donc profité d'une conjoncture cyclique favorable à partir de 1808 .

Pour le gouvernement colonial, les revenus restaient faibles et les rentrées fiscales rapportaient peu, même dans le domaine des douanes, perçues par les fonctionnaires du Bas-Canada, une servitude qui engendra bien des plaintes. Heureusement pour les colonies, les Britanniques firent de gros versements, à plusieurs titres: les compensations pour les pertes subies par les loyalistes durant la Révolution, de grandes sommes versées entre 1785 et 1795 ; les soldes et les demi-soldes payées aux officiers, au nombre de 110 en 1807; la subvention annuelle que Londres versait aux fins de l'administration de la province; les salaires du département des

\footnotetext{
${ }^{37}$ McCalla, op. cit., p. 6.

${ }^{38}$ McCalla, op. cit. (voir notamment les chapitres 2, «The Loyalist Economy, 1784-1805», pp. 13-29, et 3, "The War Economy and After, 1806-1822», pp. 30-42).

${ }^{39}$ Ouellet, Histoire économique et sociale..., pp. 41-42.
} 
Affaires indiennes. À côté des dépenses civiles d'environ $10000 \mathrm{E}$ sterling par année, il y avait surtout la plus grosse dépense, celle de l'armée qui devait se nourrir, en plus d'entretenir ses garnisons ${ }^{40}$. Avant 1803, les dépenses militaires britanniques dépassaient en valeur les exportations. Ces déboursés eurent un effet considérable sur les importations et sur le commerce de détail, puisque les officiers à pleine solde et les officiers retraités recevant une demi-solde achetaient divers objets en provenance de la Grande-Bretagne. D'ailleurs, ils se plaignaient beaucoup des prix élevés qui avaient cours dans le Haut-Canada.

Déjà, à cette époque, l'agriculture commençait à s'imposer comme la première activité économique de la colonie, alors que la coupe du bois, après 1805 , se développa rapidement. Mais au début du XIX ${ }^{\mathrm{e}}$ siècle, la fourrure n'avait pas encore disparu. La région du Détroit en produisait encore beaucoup. Tant les Amérindiens que les trappeurs échangeaient des pelleteries contre des produits importés. Le système des transports devenait donc un élément critique dans les échanges et affectait le prix des marchandises transportées sur de longs parcours. À l'époque, le transport des marchandises se faisait surtout par voie d'eau ${ }^{41}$. Plusieurs des grands marchands de l'époque, tels Robert Hamilton, Richard Cartwright et Quetton de Saint-Georges, avaient commencé leur carrière de grands marchands dans l'équipage de navires et dans le transport des fourrures en $\mathrm{canot}^{42}$. Ce régime de transport avait aussi des conséquences sur le ravitaillement militaire. Pour soutenir ce réseau de distribution, divers bateaux furent mis en service entre les ports intérieurs. Les routes de terre étaient rares et souvent impraticables par temps pluvieux.

\footnotetext{
${ }^{40}$ McCalla, op. cit., p. 19.

${ }^{41}$ Pour une description des aléas de ces déplacements, voir le document édité par M.M. Quaife, «From Detroit to Montreal in $1810 »$, dans Canadian Historical Review XIV, n 3, 1933, pp. 293-296, à propos d'un voyage effectué vraisemblablement par Jacques Lacelle, de Détroit.

${ }^{42} \mathrm{McC}$ alla, op. cit., p. 23.
} 
Quant au commerce de détail, la lenteur de sa progression s'expliquait par le faible nombre d'habitants dans la colonie, par le niveau de vie modeste de sa population, par le manque de numéraire ou de sources de financement, enfin par la difficulté de faire circuler les biens. McCalla, qui a étudié le commerce et ses institutions dans son ouvrage d'histoire économique de la période, démontre, pour certains marchands en vue, l'importance des réseaux de transports et de crédit ${ }^{43}$. Il note aussi leur "pluriactivité ", car les marchands sont importateurs, exportateurs, grossistes, spéculateurs fonciers, intermédiaires financiers, n'hésitant même pas à pratiquer, au besoin, le troc. Ces gens d'affaires furent actifs dans le commerce et en politique, s'efforçant de maintenir de bonnes relations avec ceux qui contrôlaient les réseaux d'échanges et de crédit basés à Montréal, à Québec et à Londres. La spécialisation des marchands ne se produisit que lentement, et seulement dans les grands centres; dans les endroits moins peuplés, on trouvait souvent des marchands généraux, vendant de tout (mercerie, quincaillerie et épicerie), aidés de plus en plus par le développement des transports et par le système provincial de crédits et de paiements ${ }^{44}$. Avec le temps, chaque village eut son marchand général.

Au début du XIX ${ }^{e}$ siècle, il n'existait pas encore de distinction très nette entre le commerce de gros et le commerce de détail. Car la croissance des ventes au détail, avec ce qu'elle impliquait - l'économie monétaire, la disponibilité des produits de consommation, la présence de nombreux salariés -, était un nouveau phénomène commercial. En fait, la différenciation progressive entre les deux fonctions de gros et de détail devint un signe certain marquant le passage vers une économie monétaire qui, justement, permettait tout à la fois d'accroître les échanges, de mettre en

\footnotetext{
${ }^{43}$ McCalla, op. cit., surtout le chapitre 9, «The Provincial Business System: Trade and Financial Institutions, 1821-51», pp. 141-161.
}

${ }^{44}$ Ibid., p. 142. 
place un meilleur réseau d'approvisionnement et de favoriser la spécialisation des commerces. En attendant cette spécialisation des marchands et la distinction entre le détail et le gros, le même marchand jouait des rôles différents selon les circonstances ${ }^{45}$. Par exemple, à York, certains marchands, comme J. S. Baldwin, Jules-Maurice Quesnel ${ }^{46}$ ou Quetton de Saint-Georges, firent à la fois le commerce de détail et le commerce de gros. Car l'approvisionnement régulier de leurs magasins, éventuellement leur spécialisation, n'était possible que dans les centres les plus peuplés.

Peu à peu s'organisa la structure des échanges. Au début du XIX ${ }^{e}$ siècle, l'organisation du commerce de détail au Canada pouvait se présenter sous la forme d'une pyramide. Cet organigramme ressemblait en tout point au régime mis en place pour assurer la coupe du bois et son exportation en Grande-Bretagne, avec ses grandes sociétés anglaises achetant le bois, avec les exportateurs établis dans le port de Québec, avec les entrepreneurs détenant des droits de coupe et avec les sous-traitants qui recrutaient les bûcherons et organisaient les chantiers forestiers ${ }^{47}$.

Dans le domaine de la vente des marchandises, on trouvait aussi, au plus haut niveau, les grandes sociétés britanniques, désireuses d'écouler leurs produits vers les colonies. Elles ne traitaient qu'avec un petit nombre de négociants implantés dans les villes portuaires outre-mer. C'est le deuxième niveau, celui des marchands-négociants. Ceux-ci faisaient le commerce de gros et se spécialisaient dans l'import-export. Ils couraient le risque des grands

\footnotetext{
${ }^{45}$ Ce phénomène a été étudié pour York dans les années 1820: T.W. Acheson, "The Nature and Structure of York Commerce in the 1820s", dans Canadian Historical Review 50(4), décembre 1969, pp. 406-428.

${ }^{46}$ Peter Deslauriers, "Quesnel, Jules-Maurice (baptisé Julien-Maurice)", dans DBC Volume VII de 1836 à 1850, [Québec], Presses de l'Université Laval, [c1988], pp. 775-777.

${ }^{47}$ Sur le commerce du bois, voir Arthur Lower, Great Britain's Woodyard. British America and the Timber Trade, 1763-1867, Montréal, McGill-Queen's University Press, [c1973], xiv-271 p.
} 
entrepreneurs, investissaient dans les institutions financières et récoltaient parfois de gros profits. Ils étaient les seuls à pouvoir commander à l'extérieur de la colonie et à disposer des fonds nécessaires à ces grandes opérations commerciales. Leur rôle dans la ville de Québec, le seul port de mer transatlantique dans les Canadas capable à l'époque de recevoir des centaines de navires, a été bien étudié par George Bervin ${ }^{48}$.

Ces marchands-négociants entretenaient des rapports avec les marchands moyens qui formaient le troisième niveau de la pyramide. Ces commerçants, occupant un rang subalterne, devaient se rendre dans les grands centres comme Québec ou Montréal, pour s'approvisionner auprès des négociants, pour se procurer une variété de marchandises, souvent à l'encan, et, à l'occasion, pour obtenir le crédit nécessaire. Autrement, il aurait fallu aller acheter dans les villes portuaires américaines comme New York, ce qui posait d'autres difficultés. Les marchands moyens dépendaient des marchands-négociants pour leur approvisionnement en marchandises, y compris le choix des produits importés. Ils écoulaient ensuite ces biens un peu partout dans les villes du Bas et du Haut-Canada. Au fil des années, les marchands moyens luttèrent pour accroître leur part de marché, mais la plupart ne possédaient qu'un seul magasin ${ }^{49}$. Enfin, au bas de la pyramide se trouvaient les petits marchands locaux et les marchands ambulants. Verchères de Boucherville, malgré toutes ses relations sociales, n'occupa rien d'autre que les plus bas échelons.

Une vue semblable des choses est proposée par l'historien Claude Pronovost ${ }^{50}$. Au sommet de la pyramide, il place les manufacturiers, généralement établis dans les

\footnotetext{
${ }^{48}$ George Bervin, op. cit., passim.

${ }^{49}$ Bervin, op. cit., pp. 66-72.

so Voir Claude Pronovost, La Bourgeoisie marchande en milieu rural (17201840), Sainte-Foy, Presses de l'Université Laval, "Géographie historique", 1998, x-230 p.
} 
grandes villes d'Europe ou d'Amérique. Ils fournissent un éventail de produits aux négociants ou grossistes installés dans les centres plus importants comme Montréal et, de plus en plus, York. Sous ce deuxième niveau, se trouvent les marchands établis non seulement dans les villes et les villages, mais dans les milieux ruraux.

Les activités de Verchères de Boucherville dans le HautCanada illustrent à la fois la précarité des transports, avec leurs délais ou leur manque de régularité, et l'importance, au début du XIX ${ }^{e}$ siècle, du crédit. C'est l'huile qui permet à ces rouages de fonctionner, tant le crédit que le marchand reçoit de ses fournisseurs que celui qu'il accorde à ses clients. Dans les zones périphériques comme Amherstburg, le troc se pratiquait encore fréquemment dans les échanges. L'endettement était très généralisé et les marchands supportaient toujours d'énormes charges financières, tout en devenant eux-mêmes des prêteurs. Pourtant, certains observaient à cet égard de grands progrès, comme James Strachan, qui visita le Haut-Canada en 1819 et nota que "The inhabitants have been roused into action and enterprize by the certainty of goods and ready markets for their produce, and the vast accession of capital diffused through the provinces by the late war ${ }^{51}$ n.

L'armée était la grande consommatrice dans la colonie et elle achetait beaucoup de marchandises de toutes sortes. Mais elle ne distribuait pas ses contrats d'approvisionnement à tout venant. Car les grands bénéficiaires, presque les seuls, des gros contrats de fournitures et d'alimentation étaient surtout les marchands-négociants ${ }^{52}$. Les marchands moyens ne recevaient que les miettes de peu de valeur. Néanmoins, même un petit commerçant pouvait profiter

\footnotetext{
${ }^{51}$ James Strachan, A Visit to the Province of Upper Canada in 1819, Aberdeen, 1820, (S.R. Publishers Limited, Johnson Reprint Corporation, 1968), p. 31. ${ }^{52}$ Bervin, op. cit., p. 67 . Voir notamment le chapitre IV: «Les liens d'affaires entre les grands marchands et l'administration militaire du Bas-Canada", pp. 163-203.
} 
Verchères de Boucherville dans le Haut-Canada

de la présence de l'armée. Pour s'approcher des contrats de fourniture ou pour vendre aux militaires, il fallait fréquenter ces derniers.

La région du sud-ouest du Haut-Canada était encore, au début du XIX ${ }^{e}$ siècle, une zone marginale où le commerce des fourrures, les relations avec les tribus amérindiennes et les conflits avec les Américains restaient des questions préoccupantes pour les autorités coloniales. Les terres y avaient été acquises des Mississagués en 1790, mais la colonisation commençait à peine. La présence militaire britannique exerçait une influence déterminante qui se manifestait surtout, dans cette région entre les lacs Huron et Érié, par les activités de garnison du fort Malden, à Amherstburg. C'est là, près du fort britannique, que Boucher de Boucherville alla établir son commerce, dans le voisinage de l'armée, plutôt qu'à Sandwich (l'Assomption), en face de Détroit. D'autres commerçants, comme la famille Baby, vivaient à Sandwich.

En 1815, Joseph Bouchette publiait à Londres sa Description topographique de la province du Bas[-]Canada avec des remarques sur le Haut-JCanada, contenant la description d'Amherstburg et de Sandwich:

cette ville [Amherstburg] est située sur la rive orientale de la Rivière Détroit en la remontant environ trois milles, et contient environ cent cinquante maisons, une église, une cour de justice, une prison, $8 \mathrm{c}$. C'était une place frontière, et un dépôt naval, mais les ouvrages militaires, le chantier et les magasins furent détruits en 1813 par les Anglais, qui furent contraints par une force supérieure d'évacuer la place: il y a un havre sûr et commode, et un bon ancrage avec trois brasses et demie d'eau. Quatorze milles au-delà d'Amherstburg, en suivant le cours de la rivière, on trouve la ville de Sandwich, qui contient environ cent maisons, une église, distinguée par le nom de l'église des Hurons, une cour de justice, et une prison: il y a des quais le long de la rivière, où les navires peuvent être en sûreté pendant l'hiver ${ }^{53}$.

${ }^{53}$ Joseph Bouchette, Description topographique de la province du Bas[-]Canada avec des remarques sur le Haut[-]Canada, et sur les relations des deux provinces avec les Etats[-]Unis de l'Amérique, Londres, 1815, pp. 637-638. (Réédition 
C'est dans cette région décrite par Bouchette que se retrouva bientôt Thomas-Verchères de Boucherville.

Durant la période de 1806 à 1816, Verchères de Boucherville fit cinq séjours à Amherstburg (1806-1811, 1811-1813, 1813, 1815, 1816), entrecoupés par des absences plus ou moins prolongées. Durant les années $1806-$ 1811 , il vint exploiter un petit commerce de détail, d'abord en sa qualité de commis travaillant pour le compte de Quetton de Saint-Georges (1806-1808), puis à son propre compte après 1808. En 1811, il s'absenta plusieurs mois et revint plus tard dans l'année. En janvier 1813, il quitta Amherstburg une deuxième fois, mais revint la même année, chargé de marchandises. À la fin de 1813 , Verchères de Boucherville quitta la région en même temps que les troupes britanniques en déroute devant l'invasion américaine. En 1815, il revint à Amherstburg pour son quatrième séjour, mais ne réussit pas à y rétablir son commerce. Enfin, il songea de nouveau à s'établir à Amherstburg en juillet 1816 , mais dut abandonner son projet. Il renonça alors au commerce et revint à Boucherville, comme dit le poète, «Vivre entre ses parents le reste de son âge!» (Joachim du Bellay).

\section{B. Le COMmis de QuetTon de SAINT-Georges}

Après son retour à Boucherville en 1804, le jeune homme de dix-neuf ans revenu hâtivement du Nord-Ouest se retrouvait sans moyen de gagner sa vie. Thomas-Verchères de Boucherville pensait cependant à se lancer dans le commerce, alors que son père se faisait des soucis pour un fils qui restait "sans aucune occupation sérieuse». Comme l'explique l'auteur du Journal, "je ne connaissais à qui m'adresser pour cela, car je ne connaissais personne. Je n'osais demander à mon cher père de s'intéresser pour moi

par John Hare: Montréal, Éditions Élysée, 1978.) La brasse mesure cinq pieds, soit environ 1,6 mètre. 
auprès de quelques marchands de réputation à Montréal, l'ayant si souvent trompé par mes incartades avant mon départ pour les pays d'en haut». C'est sa mère qui intercéda auprès du père: "ma mère fut forcée de le solliciter beaucoup et longtemps avant de pouvoir le faire fléchir sur mon compte. Enfin, elle y parvint» (JVB 39).

Le hasard fit que Quetton de Saint-Georges passa par Boucherville pour voir Louis-René Chaussegros de Léry, le beau-frère de Verchères de Boucherville. Au cours d'un dîner, «la conversation s'engagea sur les affaires commerciales, incidemment; [et il] dit qu'il allait perdre un excellent commis, qui le quittait dès son retour à York, et qu'il désirait beaucoup avoir un jeune [C]anadien pour le remplacer; son nom était Vigneau et il venait de Boucherville même" (JVB 40). Aussitôt, la mère "saisit la balle au bond" et demanda le poste pour son fils. Le jeune Boucherville déclara ne craindre "ni la misère ni le travail" (JVB 41). Les arrangements furent vite conclus et le nouveau commis partit trois jours plus tard. On était en octobre 1804. Ainsi commençait une grande amitié. Dans son Journal, Boucherville laissa de son ancien patron un portrait révérencieux, le décrivant comme "un Monsieur, d'origine française, venu au pays, depuis peu d'années, avec un groupe d'amis, (des royalistes) parmi lesquels était le comte de Puisaye avec l'intention de se fixer dans le Canada» (JVB 39-40).

Les tentatives de colonisation des émigrés royalistes furent un échec et le comte de Puisaye rentra en Angleterre en $1801^{54}$, mais sa maison de Niagara-sur-le-Lac (Newark) fut convertie par Quetton de Saint-Georges et Ambroise de Farcy, un officier royaliste, en magasin vendant diverses marchandises. Quetton de Saint-Georges tenait à York un commerce de détail, sous la raison sociale Quetton St George and Company, une entreprise dont il fut l'unique propriétaire

${ }^{54}$ N.-E. Dionne, op. cit., p. 151. 
jusqu'en 1815. Il s'approvisionnait à Montréal et à New York. Comme les marchands de l'époque dans le HautCanada, Quetton de Saint-Georges ne se limita pas à vendre des marchandises d'importation et des produits locaux, il joua aussi un rôle de créancier. Il dut établir son réseau de communication, écrire beaucoup, choisir des commis et déléguer des responsabilités. Quetton de Saint-Georges menait ses commis avec fermeté, après les avoir recrutés parmi les «jeunes gentlemen", à qui il faisait confiance. Il cultiva de bons rapports avec le gouvernement colonial et avec l'armée. Comme Alexander Wood et William Allan, il était à York une figure dominante dans le monde des affaires. Mais l'élite yorkaise ne l'accepta jamais complètement, peut-être parce que certains membres de ce corps social avaient de grosses dettes à lui rembourser. Son meilleur ami était le docteur William Warren Baldwin, chef de file réformiste.

Quand il entra en 1804 au service de Quetton de SaintGeorges, le jeune commis de Boucherville fut aussitôt envoyé à Lachine porter une lettre destinée à un certain Grant, qui était l'agent du marchand de York. Il fallait appareiller le bateau afin de partir le lendemain. On atteignit Kingston sans problème. Dans cette ville, Quetton de Saint-Georges conduisit son jeune employé «chez un de ses amis, émigré français comme lui, du nom de Boiton" (JVB 41). À Kingston, Boucherville rencontra aussi un monsieur Foretier [Fortier? Forestier?], résidant dans cette ville, «un ancien ami de M. de Léry, [s]on beau-frère, aussi bien que de [s]on frère, tous s'étant fort bien connus lorsqu'ils étaient au Royal Canada" (JVB 41-42). Ce régiment avait été mis sur pied en 1796 par le gouverneur lord Dorchester (Guy Carleton), avant son départ, pour remplacer les troupes anglaises. Il s'agissait d'un bataillon canadien-français. Comme dans le Nord-Ouest, Boucherville continuait de nouer de nouvelles relations sociales et militaires. Puis on navigua jusqu'à York, à l'autre 
bout du lac Ontario. Peu après son arrivée, Boucherville passa quelques jours chez René-Auguste, comte de Chalus, et le vicomte son frère, des amis de Quetton de SaintGeorges, vivant à quatre ou cinq lieues de York ${ }^{55}$.

Au comptoir le plus important, à York, travaillaient trois commis: un teneur de livre, John Dettor, un premier préposé au détail, John McDonald, et un second, Édouard Vigneau, que le jeune Verchères de Boucherville venait remplacer. Selon la règle en vigueur dans la maison, les travaux les plus pénibles du magasin étaient confiés aux derniers arrivés: «aussi en eusses-je [sic] ma grande part durant une année" (JVB 42-43). Le jeune commis arrivait à temps, puisque l'automne était l'époque de la réception des marchandises.

En 1806, Quetton de Saint-Georges exploita une succursale à Kingston, tenue de 1806 à 1810 par Augustin Boiton de Fougères, un officier royaliste, une autre à Niagara, dirigée par Charles Fortier jusqu'en 1808, et une encore à Amherstburg sous la raison sociale Boucherville et McDonell, enfin une dernière au lac Ontario, située à Dundas et dirigée par H.S. McKay ${ }^{56}$. Dans tous les cas (York, Kingston, Niagara, Amherstburg), à l'exception de Dundas, il s'agit d'«agglomérations promises à un bel avenir commercial, mais aussi des centres qui accueillaient la petite garnison britannique de la province». Au début, Quetton de SaintGeorges correspondait en français avec tous ses magasins (sauf celui de Dundas). Les pelleteries perdaient rapidement de leur importance et il fit de plus en plus le commerce de la farine et de la potasse. À Dundas, McKay exploitait aussi une distillerie et une fabrique de potasse. Comme on trouvait encore des fourrures à acheter auprès

\footnotetext{
${ }^{55}$ Selon N-E Dionne, op. cit., Chalus était major-général. Il avait reçu des terres dans le canton de Markham (p. 137), soit 350 acres (p. 148), mais s'était apparemment fixé à Niagara et à Windham (p. 150).

${ }^{56}$ Douglas McCalla, «Quetton St George, Laurent I. .]», dans DBC Volume VI de 1821 à 1835 , p. 688 .
} 
des Amérindiens de la région, Boucherville eut l'occasion de visiter plusieurs villages mississagués des environs ${ }^{57}$.

C'est en juillet 1805 que se produisit l'épisode rocambolesque qui affermit la confiance du marchand envers son jeune commis. Un débiteur de Quetton de Saint-Georges, traité de «fripon» dans le Journal, s'était enfui sans acquitter ses dettes. Verchères de Boucherville partit à ses trousses deux jours plus tard, en canot, accompagné d'un Amérindien et d'un ami nommé Cameron. Il se rendit à Niagara où monsieur de Farcy le conduisit «chez le C[om]te de Puisaye " et lui donna « un bon et vigoureux cheval». Verchères de Boucherville trouva finalement la piste de son homme dans une hôtellerie à Chippewa et le fit arrêter à Fort-Érié. Le prisonnier fut ramené à York par les autorités et mis en prison. Au retour, Boucherville s'arrêta à «l'établissement du Comte de Puisaye" (nom mentionné une deuxième fois, sans dire que le comte était depuis longtemps parti!), puis à Niagara où il avait laissé Cameron. Il reprit le schooner Toronto qui le ramena à York et à son patron reconnaissant: "La nouvelle de l'arrestation de son malhonnête débiteur lui causa un vif plaisir, et dès ce moment, il plaça toute sa confiance en moi» (IVB 44-45).

À l'hiver de 1806, Boucherville fut envoyé acheter des pelleteries chez les Mississagués, ce qui augmenta encore plus son crédit, nous apprend le Journal. Il put mettre à profit les connaissances de la traite acquises plus tôt dans le Nord-Ouest. Le jeune commis apprenait le métier de marchand. Il passait toutes ses soirées à faire des factures ou à les consigner dans des registres. Il traitait avec d'autres marchands en Angleterre, aux États-Unis et à Montréal. Pour le reste, les transactions avec les habitants occupaient les commis de cinq heures du matin jusqu'à dix ou onze heures du soir (JVB 46). Heureusement, les affaires

${ }^{57}$ Ibid., p. 689; F.H. Armstrong, «Boucher de Boucherville, Thomas-RenéVerchères", dans DBC Volume VIII de 1851 à 1860, p. 112. 
allaient bien puisqu'on apprit, une fois l'inventaire terminé, que l'entreprise avait accumulé un profit de vingt mille louis. Ce commentaire démontre en même temps que cet important marchand ne tenait pas des registres de comptabilité à doubles entrées, ce qui lui aurait régulièrement donné un bilan comptable montrant l'état financier de son commerce.

Au printemps de 1806, Quetton de Saint-Georges se rendit à New York pour acheter les nouvelles marchandises de l'été. Il fut absent deux mois. C'est alors que le marchand décida d'envoyer son jeune commis à Amherstburg «pour y ouvrir une succursale de son établissement, prévoyant qu'il y ferait d'excellentes affaires, vû [sic] le luxe qui régnait parmi une certaine classe de ses habitants» (JVB 47). Boucherville, qui regrettait d'avoir à quitter Quetton de SaintGeorges, partit avec «un assortiment de marchandises, de la valeur d'à peu près de $£ 2500-0-0$ stg, avec lequel je m'en allai» (JVB 47). Il passa par Niagara, Queenston et FortÉrié. Il attendit douze jours avant de pouvoir s'embarquer sur une goélette américaine qui, en trois jours, l'amena à Détroit. Il régla ses affaires avec les douanes américaines, loua une chaloupe et se fit conduire sur la côte canadienne.

Boucherville s'empressa de retrouver des connaissances, comme ce dénommé Maisonville «un de [s]es anciens camarades de collège, dont le père était l'ami du [s]ien». Il rencontra aussi Frédéric Rolette, commis, qui avait combattu et été blessé aux batailles d'Aboukir et de Trafalgar, et qui jouerait plus tard un rôle important dans certains épisodes maritimes de la Guerre de 1812.

Quant aux marchandises apportées par Boucherville, elles furent transportées dans un coffre-fort, «propriété de M. W. Duff, marchand de la place, en attendant l'ouverture de [s]a propre boutique» (JVB 49). Le commis chercha un local approprié au commerce. Il se renseigna aussi sur les affaires, prenant «des renseignements sur les apparences 
générales des affaires commerciales et des espérances qu'elles pouvaient faire concevoir. Celles-ci n'étaient point de ces meilleures [sic]; l'argent était rare, et les transactions ne se fesaient [sic] que pour du blé d'inde (maïs), de la farine, etc.» (JVB 49). Cette morosité des affaires inquiéta Boucherville qui s'alarma un peu. Il loua une grande chambre où il put à la fois se loger et exposer «le mieux [. .] possible, [s]on assortiment bien choisi et fort convenable de marchandises» (JVB 50). Dès le premier jour, il fit des ventes de 200 piastres, puis continua son commerce tout l'été (JVB 51). Le Journal décrit ainsi son succès: "Mes affaires continuèrent de bien aller, je suis heureux de le dire, et mes remises à $M$. de St. Georges se faisaient régulièrement à ses mandataires desquels je recevais des lettres de change sur la maison Englis, Ellice \& Co., à Londres, et le Commissaire-Général Robinson à Québec» (JVB 52).

Entre-temps, Boucherville continuait à cultiver son réseau de fréquentations. Il se fit un ami de Frédéric Rolette: "J'appris qu'il était de Québec, et un peu allié à l'ancienne et respectable famille Bouchette" (JVB 50). Le jeune Rolette avait le même âge que Boucherville et était commis du marchand Robert Reynold, lequel avait épousé une Bouchette, membre de la famille de l'arpenteur général Joseph Bouchette. Ils se lièrent d'une amitié qui dura toute leur vie. Boucherville fréquenta aussi l'honorable Jacques Baby: «Le premier dimanche de mon séjour, j'allai faire visite chez M. Jacques Baby qui [ne] m'était pas inconnu, l'ayant vu chez mon père, et aussi à Messire Marchand le curé résidant à Sandwich, à environ six lieues d'Amherstburg. J'arrivai durant la grande messe" (JVB 51). Le curé Marchand se souvenait d'avoir vu Boucherville au Collège de Montréal, alors qu'il en était le directeur. Le jeune commis fréquenta aussi Maisonville: "J'allai aussi me présenter chez M. Maisonville père" (JVB 52). 
Boucherville dresse un portrait agréable de la région, avec son bon climat, ses riches terres, ses eaux poissonneuses et ses beaux bâtiments, surtout du côté britannique. Le Journal montre que son auteur s'est bien plu dans la région d'Amherstburg, dont il garda toujours de beaux souvenirs de jeunesse.

\section{BOUCHERVILLE À SON PROPRE COMPTE}

Le Journal ne fait pas état des activités commerciales de 1807, mais rapporte qu'au printemps de 1808, Quetton de Saint-Georges proposa à Boucherville d'ouvrir son propre commerce, un geste posé en reconnaissance de ses services. Le marchand de York se porterait garant des achats de Boucherville chez les fournisseurs de Montréal et de New York pour toutes les marchandises dont il aurait besoin. Le commis de vingt- trois ans était très satisfait de la proposition: "Inutile de dire que j'acceptai avec reconnaissance ses gracieuses offres. De suite, je fis l'inventaire des effets qui me restaient et le lui communiquai. Sans entrer dans plus de détail, je dois dire que mon petit commerce fut toujours très florissant.» Le Journal est avare de commentaires sur les activités commerciales de Boucherville dans les années suivantes, mais il nous apprend au moins qu'en 1810 , le jeune marchand avait accumulé des profits de deux mille louis (JVB 53). C'est tout ce que nous savons sur les activités de la période allant de 1808 à 1811 .

Mais nous pouvons au moins entrevoir le rôle du crédit et l'importance des garanties données par des hommes solvables jouissant d'une bonne réputation et de ressources suffisantes. Le Journal laisse aussi voir le mécanisme d'approvisionnement des marchands éloignés auprès des grossistes à Montréal et à New York. Ce document montre encore que les petits marchands préféraient l'argent sonnant et trébuchant, mais que les circonstances les poussaient souvent à pratiquer le troc. Les marchands de gros, 
dans les grandes villes, devaient à leur tour acheter des produits, localement ou à l'extérieur du continent. C'était le cas de Quetton de Saint-Georges. Ainsi, Boucherville se rendit à York en 1811 et se déplaça ensuite en compagnie de Quetton de Saint-Georges jusqu'à Montréal pour «y faire des achats». Apparemment, pour la période 18081811 , ce serait Quetton de Saint-Georges qui aurait acheminé vers Amherstburg les marchandises dont Boucherville avait besoin, ou encore des marchands ayant reçu du riche homme d'affaires de York des garanties de paiement.

Quelles étaient les activités de Boucherville? Il vendait des marchandises dans son magasin. Nous savons aussi qu'il faisait la traite des fourrures: «Je connaissais parfaitement ce lieu [Pointe-Pelée], situé à une quarantaine de lieues d'Amherstburg, car j'y tenais pour mon compte des sauvages que j'employais à chasser l'ours et le chat sauvage qui s'y trouvaient en grande quantité » (JVB 56). Aux Amérindiens, qui l'appelaient Moniconini, il achetait fourrures et sucre d'érable ("cassonade du pays"). Il leur remettait aussi des cadeaux, par exemple «une vingtaine de brasses de tabac et [. . ] un baril de rhum de dix gallons, ce qui mit le comble à leur joie» (JVB 66).

Éloigné d'Amherstburg pendant une partie de 1811 , Boucherville craignait pour ses affaires. Il écrit dans son Journal: «l'inquiétude me gagnait au sujet de ma maison, l'ayant laissée aux mains de commis peu versés dans les affaires mercantiles, et que mon commerce pouvait réellement souffrir de cette absence prolongée» (JVB 56). Mais ce sont surtout les affaires de Quetton de Saint-Georges qui semblaient compromises. L'un et l'autre risquaient de tout perdre. Quetton de Saint-Georges approvisionnait plusieurs marchands dispersés: le comptoir de York, tenu par J.S. Baldwin et Jules-Maurice Quesnel, celui de Niagara, tenu par Despard, celui de la Tête-du-Lac (Burlington), tenu par J. McKay. Agissant en grossiste, Quetton de SaintGeorges avait, en 1811, commandé des marchandises aux 
Verchères de Boucherville dans le Haut-Canada

États-Unis, à New York et à Schenectady, pour une valeur de 58000 dollars. Messieurs Walton $\& \mathrm{C}^{\mathrm{ie}}$ devaient acheminer le tout à York. Mais les États-Unis, au bord de la guerre contre la Grande-Bretagne, venaient d'adopter en 1809 le Non-Intercourse Act, une loi interdisant la circulation des marchandises vers les colonies britanniques. Ainsi, la douane américaine à Lewiston, sur la rivière du Niagara, dans l'État de New York, confisqua les marchandises destinées à Quetton de Saint-Georges (JVB 55).

À l'insu de son ancien patron, Boucherville, qui était alors de passage à York, forma le projet de reprendre «les effets illégitimement confisqués et détenus à Lewiston par les Américains" (JVB 56). Il rejoignit Despard, commis de Quetton de Saint-Georges à Niagara, pour exécuter son projet de saisir les marchandises, gardées dans un hangar près du rivage, du côté américain. Il rencontra aussi le marchand Joseph Chinic, officier du Royal Canadien, et l'intéressa au projet d'aller de nuit reprendre les marchandises, puisque Quetton de Saint-Georges était «un de [s]es meilleurs amis» et qu'il lui avait rendu de nombreux services. Les trois complices s'organisèrent: "Nous décidâmes d'engager un nombre de [C]anadiens sobres et discrets avec plusieurs bateaux dans l'un desquels on placerait une échelle destinée à nous aider à monter au second étage du hangar, la demeure du douanier" (JVB 59). L'affaire fut exécutée avec grand succès, en secret, par une quarantaine d'hommes. En pleine nuit, le douanier américain fut surpris, les marchandises furent chargées dans les bateaux et l'expédition revint à Queenston (voir la CARTE II). Les Américains offrirent une récompense de 1000 piastres pour ramener mort ou vif l'un des responsables (JVB 62).

Boucherville se rendit à York pour rendre compte à son ancien patron du succès de l'opération à Lewiston. Quetton de Saint-Georges le présenta au lieutenant-gouverneur Francis Gore qui, selon le Journal, rassura Boucherville: le gouvernement ne le livrerait pas aux Américains pour cette 
affaire de contrebande. L'opération sauva Quetton de SaintGeorges qui fit de belles affaires quand éclata la Guerre de 1812. Il put alors se faire «une fortune d'une centaine de mille louis" (JVB 64). Après avoir passé quelques jours avec son ami de York, Boucherville rentra à Amherstburg où il découvrit que «[s]es affaires n'avaient point souffert de [s]a longue absence.» (JVB 64).

L'épisode de Lewiston, en 1811, montre le lien entre le commerce et les affaires militaires. Pour Boucherville, ce fut aussi une aventure: «Ce fut là la plus belle prouesse de ma vie, ainsi que l'acquittement envers mon protecteur d'une véritable dette de gratitude que je lui devais, je ne saurais le répéter trop souvent" (JVB 64). La vie de marchand général réussissait bien à Boucherville.

Mais la région d'Amherstburg, comme les autres parties de l'Empire britannique en Amérique du Nord, était sur le point de s'embraser. Les bruits de guerre grondaient depuis des années. Elle éclata en juin 1812.

\section{IV - GUERRE ET COMMERCE 1812-1816}

La plus grande partie du Journal de Verchères de Boucherville est consacrée à la Guerre de 1812 , ce qui montre bien l'importance que son auteur accordait à ces événements, plus particulièrement aux souvenirs qu'il en avait conservés. En fait, la participation du marchand d'Amherstburg se limita à quelques épisodes survenus dans le Sud-Ouest, à savoir la prise d'un bateau américain, la bataille de Brownstown au Michigan, quelques actions de petite guerre, enfin l'évacuation de la région et la bataille de Moraviantown. Le document fait le récit des souvenirs de Boucherville, mais ne propose ni analyse ni réflexion sur les événements militaires ou politiques auxquels il a participé.

Le conflit de 1812 se préparait depuis une décennie. En 1803, les Américains avaient aidé financièrement Napoléon en achetant la Louisiane à la France. En Europe, Français 
et Britanniques tentèrent d'interdire tout commerce avec leurs adversaires réciproques. Une grande partie de la flotte commerciale battait à cette époque pavillon américain. En mai 1806, la Grande-Bretagne déclara qu'elle imposerait un blocus commercial contre la France, c'està-dire l'Europe continentale. En janvier 1807, les Britanniques adoptèrent un nouveau règlement, interdisant aux bateaux neutres de commercer entre deux ports sous contrôle français, à moins d'arrêter dans un port britannique. Un troisième arrêté, en novembre 1807 , interdisait de commerce tout port dont les navires britanniques seraient exclus. Dans le Décret de Milan, Napoléon riposta en autorisant la confiscation de tout bateau neutre qui se plierait aux prétentions britanniques. Les Britanniques interceptèrent des navires américains pour les empêcher de contourner l'embargo frappant le commerce français. En 1807, un navire britannique lâcha une bordée contre un bâtiment, le Chesapeake. Cet incident donna lieu à des "regrets» de la part des attaquants, mais l'indignation était grande aux Etats-Unis et certains criaient vengeance. Pourquoi ne pas s'emparer des colonies britanniques au nord? Les rumeurs de guerre coururent.

La riposte américaine avait commencé dès 1806 par l'adoption d'une loi, dite Non-Importation Act, qui interdisait l'importation d'une liste de produits britanniques. Après six mois, cette loi fut remplacée par l'Embargo Act, qui fermait les ports américains à tout commerce étranger, ce qui provoqua une récession. La contrebande entre les États-Unis et les colonies britanniques se développa. Enfin, en 1809, les Américains adoptèrent le Non-Intercourse Act, qui bannissait tout commerce avec la Grande-Bretagne ou la France, ou avec leurs colonies.

Le 18 juin 1812, les États-Unis déclarèrent la guerre à la Grande-Bretagne, précipitant un conflit qui allait durer jusqu'aux derniers jours de 1814. La frontière canadoaméricaine et la côte atlantique s'enflammèrent. Les 
affrontements terrestres, en Amérique du Nord, se déroulèrent le long de la frontière, à Michillimakinac (entrée du lac Michigan), à Détroit-Amherstburg (passage entre les lacs Huron et Érié), à Niagara (zone entre les lacs Érié et Ontario), sur le haut Saint-Laurent (entre Montréal et Kingston), sur le lac Champlain. Les opérations navales se déroulèrent en haute mer et sur les Grands Lacs. Le SudOuest ne représentait donc qu'une partie du grand conflit nord-américain.

Plusieurs tentatives américaines d'invasion furent organisées (Détroit, Niagara, Montréal), même si, aux premiers jours, les Britanniques agirent de vitesse et s'emparèrent sans trop de mal des forts américains à Michillimakinac et à Détroit. Or, au début, il n'y avait que 2000 soldats britanniques dans tout le Haut-Canada, en plus des miliciens, des Amérindiens alliés et de quelques voyageurs. C'était bien peu pour défendre un aussi grand territoire et une frontière de 1900 kilomètres. Beaucoup de loyalistes étaient d'anciens militaires et tous les hommes entre 16 et 60 ans devaient s'engager dans la milice sous peine d'amendes. Les miliciens se regroupaient en régiments divisés en compagnies comprenant entre 20 et 50 hommes, celles-ci correspondant souvent aux townships d'origine des miliciens. Dans la suite des événements militaires, la milice fut appelée à jouer un grand rôle, tant du côté britannique qu'américain. Mais l'encadrement et la levée des milices s'avéra une tâche ardue ${ }^{58}$.

Au Bas-Canada, l'aristocratie canadienne fournit le quart environ des officiers francophones de la milice durant les années $1812-1815$ (27\% provenaient des rangs de l'aris-

${ }^{58}$ George Sheppard a décrit les difficultés de lever les milices du Haut-Canada lors de la Guerre de 1812. Il a analysé la résistance des colons récalcitrants, obligés de participer contre leur gré au service de la milice. Voir George Sheppard, Plunder, Profit, and Paroles. A Social History of the War of 1812 in Upper Canada, Montréal/Kingston, McGill-Queen's University Press, [c 1994], x-334 p. Voir notamment les chapitres 3 ( "Cool Calculators": Brock's Militia», pp. 40-67) et 4 ("A Parcel of Quakers": Militia Service, 1812-1815", pp. 68-99). 
tocratie, $25 \%$ avaient été recrutés chez les professions libérales et $41 \%$ chez les marchands). Les chiffres correspondants, du côté des officiers anglophones du BasCanada, sont: $65 \%$ de marchands, $16 \%$ de membres des professions libérales et $11 \% \mathrm{~d}^{\prime}$ aristocrates ${ }^{59}$. Boucherville, issu de la petite noblesse canadienne, héritait d'une longue tradition militaire. C'est donc naturellement qu'il rejoignit la milice locale.

\section{A. LA GUERRE DE 1812}

Quand la guerre éclata, plusieurs défis surgirent immédiatement. D'abord, l'Assemblée législative du HautCanada se montrait peu encline à prendre des mesures fermes et la population de la colonie se composait largement d'étrangers, notamment d'Américains. Aussi, la milice recrutée dans le Sud-Ouest s'avérait peu combative, alors que les alliés amérindiens, eux, restaient peu fiables ${ }^{60}$. Bref, la situation militaire inquiétait beaucoup ${ }^{61}$.

Certains marchands, cependant, ne manquèrent pas de mesurer les avantages qu'ils pourraient tirer de la conjoncture militaire. Certains pensèrent même y trouver leur compte:

They dit not even wait for a declaration of war to offer their services. [. .] The merchant groups were even ready with war plans for the authorities. They suggested as a first step the cap-

\footnotetext{
${ }^{59}$ Fernand Ouellet, «Officiers de milice et structure sociale au Québec (16601815», dans Histoire sociale/Social History XII (numéro 23), mai 1979, pp. 37-65.

${ }^{60}$ Fred Landon, Western Ontario and the American Frontier, [Introduction de Chester Martin], Toronto, Ryerson Press, [«The Relations of Canada and the United States»], 1941, p. 29.

${ }^{6}$ Sur la Guerre de 1812: George F.G. Stanley, The War of 1812. Land Operations, [Ottawa], Macmillan/National Museums of Man - National Museums of Canada, "Canadian War Museum Historical Publication" 18, [c1983], xx489 p.; Pierre Berton, The Invasion of Canada 1812-1813, [Toronto], McClelland and Stewart, [c1980], 362 p., et Pierre Berton, Flames Across the Border 18131814, [Toronto], McClelland and Stewart, [c 1981], 492 p. L'ouvrage de Stanley, en particulier, a été très utile.
} 
ture of the American post at Michil[1]imackinac and removal of the garrison from St. Joseph Island to the falls at St. Mary's. They themselves were prepared to take the offensive on Lake Superior [. . ] The zeal of "big business" interests in Canada for war with the United States has its counterpart in the attitudes of producers and merchants in the western states $\left[. .^{62}\right.$.

En fait, la guerre perturba fortement la vie commerciale et provoqua une flambée des prix. George Sheppard a pu démontrer le profit qu'un marchand habile pouvait tirer de la situation militaire ${ }^{63}$. De nombreux profiteurs firent de bonnes affaires et obtinrent de grands succès financiers en vendant leurs marchandises très cher. À York, les trois plus grands marchands (Quetton de Saint-Georges, William Allan et Alexander Wood) devinrent de grands pourvoyeurs de l'armée, vendant durant les années 1812-1815, respectivement $26731 £, 13004 £$ et $5955 £$ de fournitures. Ces marchands obtenaient dans ces contrats une marge de profit estimée à $100 \%$ sur le coût des marchandises ${ }^{64}$.

L'économie du Haut-Canada manquait toujours d'espèces et diverses sortes de monnaie circulaient. Au début de la guerre, le lieutenant-gouverneur Francis Gore avait bien essayé de mettre en circulation une sorte de monnaie provinciale, mais le projet avait échoué. Dans le Bas-Canada, le gouverneur général Prevost avait eu plus de succès avec un projet semblable. Comme le numéraire manquait, l'armée couvrit ses dépenses en distribuant des «billets de l'armée» (army bills), une sorte de papier-monnaie créée dans le Bas-Canada, mais circulant librement dans le HautCanada. Ces billets apportèrent aux échanges commerciaux de nécessaires et avantageuses liquidités. Ils étaient préférables au troc. L'automne de 1812 fut tranquille, dit le Journal, «mais les vivres étaient très chères [sic] et les

${ }^{62}$ F. Landon, op. cit., p. 28.

${ }^{63}$ George Sheppard, op. cit., surtout les chapitres 6, "Enemies at Home": Treacherous Thieves", pp. 134-170, et 7, "Success to Commerce": Costs and Claims», pp. 171-207.

${ }^{64} \mathrm{G}$. Sheppard, op. cit., pp. 145-148. 
marchandises rares». En fait, au cours de 1813, une grave crise d'approvisionnement se produisit, alors que plusieurs denrées disparurent, comme les céréales et divers produits (JVB 99). Prix forts, grands profits.

Dans le Sud-Ouest, qui seul concerne la carrière de Verchères de Boucherville dans le Haut-Canada, la guerre commença quand les Britanniques s'emparèrent du navire américain Cuyahoga, le 2 juillet 1812 . Le héros de cette capture fut le lieutenant Frédéric Rolette, que Boucherville appelle «mon ami Rolette». L'auteur du Journal précise que « [c]ette prise fut la première de la guerre et opérée par un jeune [C]anadien-[F]rançais» (JVB 70). Boucherville lui-même participa à la prise qui permit de saisir des matériaux et de faire prisonnière la fanfare qui accompagnait le général William Hull à Détroit. On obligea les musiciens américains à jouer le God Save the King.

Dès le 17 juillet 1812, plus au nord, les Britanniques, commandés par Charles Roberts, s'emparèrent du fort américain de Mackinac (autrefois Michillimackinac) dont le commandant, surpris, n'avait pas encore reçu l'avis de la déclaration de guerre. Les soldats du $10^{\text {th }}$ Royal Veterans montèrent à bord de la goélette Caledonia, propriété de la Compagnie du Nord-Ouest. Suivait une flottille de canots transportant 400 Amérindiens, commandés par le chef Tecumseh, et un groupe de voyageurs. Le fort tomba sans résistance.

Les Américains établirent leurs quartiers généraux de guerre à Albany, dans l'État de New York, sous les ordres du major-général Henry Dearborn. La grande route d'invasion passait par le lac Champlain, mais on comptait aussi envahir le Canada sur des points tels Détroit, pour réduire la menace amérindienne, à Niagara et dans les environs de Kingston (Sackets Harbor). Dans l'Ouest, les troupes et les miliciens américains étaient commandés par le général William Hull, qui s'avança à pied de la rivière Miami 
jusqu'à Détroit, où il arriva avec ses quelque 2000 hommes, le 5 juillet, quelques jours après la prise du Cuyahoga. Hull manquait de denrées et se méfiait des Amérindiens. Il reçut instruction de prendre le fort Malden, à Amherstburg, dès qu'il en aurait les moyens. Mais cela prendrait du temps avant d'obtenir des renforts. Hull lança un appel aux habitants du Haut-Canada et, le 12 juillet, des troupes américaines vinrent prendre position près de Sandwich, en territoire britannique. Aucune résistance ne l'arrêta. On fit construire des boulevards, pour résister aux attaques qui pourraient venir du fort Malden.

À Amherstburg, les troupes britanniques provenaient du $41^{\mathrm{e}}$ Régiment d'infanterie ( $41^{\text {st }}$ Regiment of foot), arrivé au Canada en 1799, sous le commandement du lieutenantcolonel Thomas St George et du colonel Adam Muir. Autour du fort Malden, il y avait des troupes régulières, mais aussi environ 400 Amérindiens et les milices locales, plus la petite marine provinciale. On laissa tomber Sandwich et la rivière La Tranche, pour concentrer les ressources à Amherstburg, afin de protéger l'accès au lac Érié.

Hull attendait avec anxiété les vivres et autres denrées qui étaient en route. Quant aux Britanniques, ils surveillaient les routes pour intercepter le passage de ces marchandises. Les responsables du convoi américain demandèrent à Hull de leur amener des renforts pour les protéger; on leur envoya des cavaliers et 150 miliciens le 4 août 1812. Le nouveau commandant du fort Malden, le colonel Henry Procter, suivait ces déplacements grâce aux informations recueillies par les Amérindiens. Il ordonna au colonel Muir d'aller avec 150 hommes et un groupe d'Amérindiens, commandés par Tecumseh, barrer la route au convoi de marchandises. Ils préparèrent une embuscade à Brownstown, situé en face d'Amherstburg, du côté américain. La bataille eut lieu le 5 août 1812. Dans cette bataille, il y eut aux côtés des réguliers britanniques, au nombre de 200, aussi 200 Amérindiens et une quinzaine 
de volontaires canadiens contre les quelque 2500 Américains qui marchaient vers Détroit.

Suite à l'appel lancé à tous les loyaux sujets, Boucherville accepta de se joindre à la milice, de bon cœur semble-t-il, comme d'autres qu'il nomme dans son Journal: Alexis Maisonville, Jean-Baptiste Barthe, James Eberts, les deux frères Cadot [Cadotte?], Alexis Bouthillier et Jean-Baptiste Baby. Verchères de Boucherville participa donc à la bataille de Brownstown, accrochage décrit dans toute sa cruauté et sa violence (prises de scalpes, férocités amérindiennes, meurtres): «'ai encore vraiment peur et me sens frissonner quand je m'en rappelle [sic]. Là se voyaient tous les cadavres, déjà en putréfaction. Des cavaliers que les sauvages avaient percés avec des piquets pour les y planter" (JVB 84). Il y eut dix-sept morts américains, dont deux prisonniers tués par les Amérindiens. Grâce à la correspondance saisie, les Britanniques connurent le mauvais état de la situation au fort Détroit.

Boucherville fut blessé au cours de l'engagement de Brownstown et il dut rentrer à Amherstburg en traversant la rivière du Détroit sur un radeau de fortune. Les volontaires canadiens blessés étaient Joseph Berthe, Jean-Baptiste Cadotte, Alexis Bouthillier, un soldat non identifié et Boucherville (JVB 93). Celui-ci explique ainsi ses sacrifices: «D'abord, je m'étais joint par amour du devoir, à l'armée de Sa Majesté mon Roi, comme volontaire, et y avais agi en bon soldat, et versé mon sang comme loyal canadien que j'étais» (JVB 91). La guérison dura dix jours, puis il alla saluer le commandant Procter, mais aussi les Baby, les Reynold, les Maisonville et autres, «sans oublier Rolette que j'aimais à l'égal d'un frère» (IVB. 92). Les marchands faisaient leur part dans l'effort de guerre.

Une autre petite bataille eut lieu à Maguaga, en face de la rivière aux Canards, le 9 août 1812 , mais Boucherville n'y fut aucunement impliqué. Il pansait ses blessures. 
Dans la région, les marchands haut-canadiens transformèrent plusieurs bateaux en canonnières, toujours appelées gun-boats. Sir Isaac Brock arriva vers le 13 août 1812 avec des troupes régulières (300), des miliciens (400) et des Amérindiens (600), toujours commandés par le chef Tecumseh, pour aller prendre Détroit. Les trois quarts de la garnison d'Amherstburg le suivirent, de même que quatre compagnies de milice, dont une dirigée par Boucherville. Ce contingent armé fit son bivouac en face de Détroit, en attendant l'arrivée de l'artillerie et de 300 Amérindiens. Brock et ses troupes avancèrent vers le nord et traversèrent la rivière du Détroit cinq kilomètres en aval du fort Détroit. C'était le 16 août 1812 . Faute de provisions, bloquées à la rivière aux Raisins, Hull pensait n'avoir aucun choix et il demanda une trêve. Apprenant en outre la perte de Michillimackinac et l'arrivée prochaine de renforts britanniques, il décida d'abandonner Détroit aux Britanniques. Malgré ses 3000 soldats et ses canons, il décida de se rendre (JVB 96). Boucherville n'a pas participé à cette reddition.

Les prisonniers furent envoyés à Montréal, mais on rapatria les miliciens de l'Ohio chez eux. Leur évacuation se fit vers Cleveland, sur la rive sud du lac Érié. Les troupes britanniques s'installèrent dans le fort Détroit, les miliciens rentrèrent à Amherstburg et Brock revint à Niagara avec ses milices d'élite. Les canons pris aux Américains, autrefois enlevés à Burgoyne durant la Guerre d'Indépendance des États-Unis, furent envoyés à Québec. Le commandant Procter, à Amherstburg, proposa à Boucherville de diriger une compagnie qui ramènerait les miliciens américains à Cleveland, mais ce dernier déclina la proposition: «je préférais de beaucoup être laissé, quelques jours encore, à mon commerce considérablement affecté par mes absences réitérées depuis le commencement de la campagne" (JVB 99).

Entre-temps, les Américains mirent en chantier la construction de leur flotte sur le lac Érié. Elle allait avec le temps 
assurer leur revanche. Ils préparaient aussi une riposte générale qui déborderait dans tout le sud de l'Ontario. Non seulement reprirent-ils Mackinac et Détroit l'année suivante, mais ils envahirent le sud-ouest du Haut-Canada. Les hostilités se poursuivirent tout au cours de 1813. Les Américains menaçaient toujours le fort Érié, à la suite de la perte du fort George (Niagara-sur-le-Lac) en mai 1813. Les Britanniques redoutaient beaucoup l'imminente suprématie des Américains sur les Grands Lacs. Ainsi, le nouveau commandant du Haut-Canada, le major général Francis de Rottenberg, se refusait à envoyer des troupes dans le SudOuest, car tout y manquait.

Les Britanniques organisèrent un corps de patrouille et d'observation qui «se composait pour bonne partie des marchands de l'endroit» (JVB 68). Le général Hull revint en 1813 à la tête d'une armée à Rivière-aux-Raisins (Monroe), à un lieu appelé Frenchtown. Les Britanniques n'avaient que quelques compagnies et de rares autochtones (on attendait le chef Tecumseh et les Potéouatamis qui le suivaient). On fortifia en vain le fort Détroit et l'on installa des batteries en face de Sandwich. Hull traversa la rivière du Détroit avec dix compagnies et s'installa en amont de Sandwich, sur le terrain de Jean-Baptiste Baby, frère de Jacques Baby. Celuici assembla les miliciens et se rendit à Amherstburg où il se réfugia quelques jours chez Boucherville, une visite «très agréable» (JVB 72).

Plusieurs escarmouches se produisirent en juillet 1813, surtout dans la région entre Sandwich et Amherstburg, au pont de la rivière aux Canards. Boucherville y accompagna un groupe d'Amérindiens ( «j'ai toujours eu la confiance des enfants des bois", JVB 73) en tenue légère, au cas où il faudrait déguerpir: "car les sauvages, du moment qu'ils se croient vaincus, ont recours à leurs jambes, et courent comme des chevreuils" (JVB 73). Plusieurs Américains furent tués par les Amérindiens («c'est la mort de leur ennemi qu'il leur faut. Aussi, quel carnage ne firent-ils 
pas!», JVB 74). Ce que Boucherville observait lui répugnait: "Je me sentis plein d'horreur pour la guerre" (JVB 74). Ailleurs, il voit aussi la beauté du spectacle: «C'était réellement un beau spectacle que de voir autant de bateaux et près de trois cents canots sauvages réunis tous ensemble" (JVB 76). Boucherville garda de cette guerre les souvenirs de carnage et de cruauté entre combattants.

\section{B. LE COMMERCE EN TEMPS DE GUERRE}

Toutes ces activités militaires nuisaient aux affaires. Non seulement le commerce de Boucherville avait-il souffert de tous ces conflits, mais une crise d'approvisionnement se produisit dès le début des hostilités: «Dans le moment [décembre 1812], mes magasins étaient entièrement vides, et je n'avais absolument rien à faire. Le commerce était totalement suspendu, car à peine aurait-on pu trouver un écheveau de fil pour raccommoder nos effets, tant à Amherstburg qu'à Sandwich et à Détroit" (JVB 101). Il fallait done reconstituer le fonds de commerce. Les troupes américaines approchaient de Détroit et le marchand avait aussi d'autres soucis, notamment celui de protéger ses biens. Il voulut cacher sa fortune: «j'allai placer en terre au coin de ma maison à l'insu de tout le monde, deux pleins gallons de doublons, de guinées et de piastres, hors de la connaissance de personne, acte indiscret s'il en fut, au cas d'accident mortel pour moi" (JVB 76) ${ }^{65}$.

\footnotetext{
${ }^{65}$ Cette diversité des monnaies en circulation dans les environs d'Amherstburg est une preuve de l'absence de numéraire. Après 1760, les Britanniques firent peu pour assurer l'approvisionnement de la colonie en monnaie. Ils introduisirent en 1763 la livre sterling (une livre vaut 20 shillings, un shilling vaut 12 deniers). La livre britannique s'échangeait contre quatre piastres espagnoles (une piastre valait donc cinq shillings). Mais les pièces britanniques n'ont jamais prévalu et de nombreuses monnaies étrangères en or ou en argent ont circulé. Les pièces d'or sont les guinées anglaises, les souverains, les «aigles» américains, les louis français, les doublons espagnols et des pièces portugaises; les pièces d'argent sont espagnoles et frappées au Mexique, d'anciennes pièces françaises, puis américaines après 1815; enfin, les pièces de cuivre en circulation sont des demi-pennies anglais et irlandais. Voir les articles "Monnaie» et
} 
Le marchand en rupture de stock venait aussi d'apprendre le décès de son père, disparu en septembre 1812. Il décida done de partir, tant pour vaquer aux affaires de son commerce que pour revoir sa mère. À Amherstburg, Boucherville confia ses affaires à son ami Woolsey qui surveillerait la maison. Boucherville partit le 5 janvier 1813, en compagnie de François Alain. Il arriva cinq jours plus tard à York où il se présenta chez Quetton de Saint-Georges. Puis il se rendit à Montréal et à Boucherville. Il passa quelque temps avec sa mère qui l'incita à se rendre à Québec, ce qu'il fit. Un de ses frères était curé à Charlesbourg, l'autre, aidede-camp du gouverneur général George Prevost. Il rendit aussi visite à «des familles auxquelles [ils étaient] alliés» (JVB 102).

Au printemps de 1813, Boucherville reçut de Quetton de Saint-Georges une lettre qui le "pressait fortement de revenir à cause de [s]es affaires mercantiles" (JVB 103). Les deux partenaires se donnèrent rendez-vous à Montréal. «Durant ce temps, je fis l'acquisition des diverses marchandises les plus nécessaires pour mon commerce, complétant mon assortiment chez MM. Gillespie $\& \mathrm{C}^{\mathrm{ie}}$ au montant de trois mille deux cents louis" (JVB 103). Certes, il y avait danger de transporter tant de marchandises en temps de guerre, «[m]ais, il n'y avait plus à tirer de l'arrière» (JVB 103). À Repentigny, il acheta quatre grands canots, chacun pouvant porter six hommes (le gouvernail, le bout et quatre rameurs), des marchandises et quelques passagers, y compris un domestique, appelé Lapointe, qui appelait Boucherville «bourgeois" (JVB 106). Les voyageurs gagnaient 50 piastres chacun, et ils travaillaient sous la direction d'un meneur, nommé Parisien, qui recevait un salaire de 100 piastres.

Par l'intermédiaire de son frère à Québec, Boucherville offrit d'apporter des munitions à Amherstburg. Le gouverneur "Monnaie légale" dans l'Encyclopédie du Canada, Montréal, Stanké, [c1987], pp. 1258-1261. 
général Prevost lui confia quatre barils de poudre (JVB 105).

Face aux dangers militaires, Quetton de Saint-Georges incita Boucherville à s'installer à la tête du lac Ontario (Burlington), mais ce dernier voulait se rendre à Amherstburg, où il disposait d'un "comptoir, quoique vide comme tous les autres, d'ailleurs. Je savais que j'y trouverais ma clientelle [sic]» (JVB 108). On traversa le lac Ontario, puis les ballots et l'équipement furent transbordés sur douze voitures tirées chacune par quatre chevaux afin de franchir la péninsule du Niagara. Puis on remit les marchandises à bord des canots pour traverser le lac Érié. On craignait les canonnières américaines, qui furent évitées de justesse. Le marchand débarqua finalement à Amherstburg avec des produits d'une valeur de $1348 \mathrm{E}$.

Les marchandises apportées de Montréal trouvèrent vite des clients assoiffés. Boucherville vendit rapidement «toutes mes boissons dont moitié de rhum de jamaïque et l'autre de vin, à raison de 10 piastres le gallon. Je ne gardai qu'une bien petite quantité de la dernière pour mon usage personnel. Je me rendis à mon établissement où je trouvai le vieux Meloche qui fut extrêmement surpris de me revoir» (JVB 118). On n'avait pas vu un marchand de Montréal depuis longtemps, personne n'ayant osé venir. Ce qui permit à Boucherville de brasser de bonnes affaires:

Le lendemain [de mon arrivée], je fus très occupé dans mon magasin et n'eus pas même le temps d'examiner mes factures et [de] mettre mes marchandises sur les rayons. Les chalands étaient aussi nombreux aux dehors qu'en dedans; c'était à qui aurait son tour. On manquait[,] voyez-vous[,] de tout dans le moment, et chacun voulait ne pas manquer l'occasion qui si heureusement se présentait. La presse devint tellement grande que je fus obligé d'employer, outre mes deux commis, quatre de mes voyageurs dont l'expérience et l'honnêteté m'étaient parfaitement connues. Mon succès fut grand, je ne puis le cacher, et j'en étais fier. Le premier jour, le détail me donna au delà de six cents louis, la journée suivante, deux cents, la troisième, quatre cents et quelques louis. 
Ce jour-là, je payai tous mes voyageurs, et aussitôt ils repartirent dans l'un de mes grands canots dont je leur avais fait cadeau en témoignage de mon estime envers eux (IVB 118-119).

L'entreprise commerciale fut en 1813 un grand succès, grâce à la hausse des prix causée par l'inflation. Celle-ci augmentait à mesure que la situation militaire se dégradait.

Tout le monde possédait des «billets de l'armée». Même les Amérindiens en avaient de grandes quantités. Ce papiermonnaie favorisait le commerce, mais contribuait à l'inflation. Partout, on préférait donc les marchandises au papier-monnaie. Les prix grimpaient pour tout, indiennes, draps, tabac, surtout le sel qui se vendait 30 piastres le minot ("c'était l'objet le plus cher», JVB 120). Boucherville en avait acheté du côté américain et il en possédait une cargaison à Cayuga, État de New York, dont il lui restait "une bonne trentaine de quarts. On peut juger du reste d'après les prix que je viens de mentionner" (JVB 120).

Entre-temps, les Américains se ressaisissaient. Après la bataille de Queenston-Heights, où le général Brock trouva la mort (13 octobre 1812), les envahisseurs prirent et incendièrent York, le 27 avril 1813. Plus tard, les Britanniques incendièrent la capitale américaine, Washington. Au cours de 1813, plusieurs batailles navales tournèrent à l'avantage des Américains sur le lac Érié, notamment leur grande victoire du 10 septembre 1813, qui les rendit maîtres des Grands Lacs en amont de Niagara (bataille de Sandusky). En conséquence, les Britanniques durent évacuer non seulement Détroit, mais leurs propres positions à Amherstburg et dans le Sud-Ouest. La déroute fut totale, surtout après la défaite de la rivière Thames le 5 octobre 1813 (bataille de Moraviantown).

À Amherstburg, on attendit cinq jours des nouvelles de la bataille maritime. Apprenant leur défaite, les Britanniques évacuèrent le fort Malden et le village d'Amherstburg et se replièrent sur Sandwich. Avant de partir, ils brûlèrent tout (hangars, casernes). Boucherville sauva ce qu'il put: «je fis 
partir, aussitôt que possible, autant de marchandises de chez moi que je le pouvais. Je les fis mettre chez des habitants de confiance qui ne pouvaient pas suivre l'armée» (JVB 122). Pour le reste, ajoute-t-il, «[j]e remis mes livres et tous mes papiers de conséquence à l'un de mes amis, homme respectable s'il en fut, plaçai sur moi, dans un mouchoir en guise de ceinture, tous les "Army Bills" que je possédais, au montant de six mille piastres, dis adieu à mes deux commis, Meloche père et fils, et sautai sur mon cheval que je mis au grand galop. J'étais le dernier à partir de tous ceux qui le pouvaient» (JVB 123).

Notre marchand en fuite arrêta brièvement chez le capitaine Bondy, puis chez Jacques Baby où il passa «plusieurs jours". On attendait l'arrivée des forces américaines à tout moment, à bord d'une flotte. On attendit en vain. Jacques Baby donna alors un grand dîner pour honorer ses invités de marque, le général Procter, le major Muir, plusieurs autres officiers, le chef Tecumseh, les frères Jean-Baptiste et François Baby, etc. Le banquet fut cependant interrompu par l'annonce que la flotte américaine remontait la rivière du Détroit.

Tecumseh voulait résister tout de suite, mais les Britanniques avaient décidé de se replier sur la Tranche (devenue la rivière Thames). Ils ordonnèrent d'évacuer le fort Détroit et de l'incendier en partant (on était le 3 octobre 1813). À Amherstburg, l'Américain William Henry Harrisson fit émettre un mandat contre ceux qui avaient suivi les troupes anglaises: "On fit la recherche des effets appartenant à ceux-ci, et les miens furent trouvés en partie chez les personnes où je les avais cachés, et apportés à la ville par un Major Zutoff» (JVB 124).

C'était la déroute complète, la fuite vers l'intérieur du Haut-Canada. Boucherville se mit en route en compagnie de Woolsey, de Voyer et d'un dénommé Bergeron, tous à cheval. Les Américains les poursuivaient de près; les 
Britanniques se retranchèrent au village des Moraves (Moraviantown). Les «Kentuckeys", comme les appelle Boucherville, arrivèrent rapidement et la bataille s'engagea. Les Britanniques furent rapidement et complètement défaits, laissant plusieurs prisonniers. Tecumseh fut tué et son corps haché en morceaux.

Boucherville et ses compagnons se firent voler leurs chevaux: "volés par les Pottawatamis [Potéouatamis] probablement, aussi grands voleurs de chevaux que le sont les B[é]doins du désert" (JVB 127). Puis l'on continua la route à travers les bois jusqu'à Oxford (London) dans un canot loué appartenant à un Larocque ou Lacroix. À partir d'Oxford, on poursuivit la route à pied jusqu'à York. Durant la marche, Boucherville perdit une chaussure, ce qui lui causa de graves ennuis.

En route, il rencontra William Claus, un ami de son père, qui venait secourir sa fille et son bébé. Les fuyards couchèrent un soir dans un village appartenant aux Six Nations: «nous nous trouvions au milieu des nôtres, des sujets anglais" (JVB 138). Verchères de Boucherville arriva enfin à Burlington-Heights où il se rendit chez McKay, commis de Quetton de Saint-Georges, puis à York, où il fut reçu chez son protecteur. Il y resta trois jours à se reposer. Il en profita pour rendre visite à madame Claus.

Ensuite, il acheta des chevaux et partit pour Montréal. Boucherville s'inquiétait du sort de Quetton de SaintGeorges: «Car je craignais les résultats de la guerre pour son négoce" (JVB 140). À Kingston, il obtint un passeport pour continuer sa route. Chemin faisant, il rencontra le capitaine Jacques Viger (JVB 142) "un camarade de collège», puis, à Prescott, il retrouva "un autre ami, le lieut[enant] Norbert Vignau» (JVB 142-143). Enfin il arriva à Montréal le 24 octobre 1813: «Nous étions en loques, quoi donc» (JVB 143). Il se rendit voir le gouverneur général George Prevost pour lui faire rapport et il rentra dans son village de Boucherville. 
Devant sa mère surprise, il compta la valeur des «billets de l'armée» et des lettres de change en sa possession. Son entourage fut surpris par les sommes: «Cela leur paraissait incroyable surtout après une absence de si courte durée» (JVB 141). Quant à la valeur de ce qui restait à Amherstburg, Boucherville réclamera plus tard des dédommagements pour des pertes de $1271 \mathrm{f}$, mais il attendra longtemps avant que le gouvernement fasse droit à ces réclamations.

Peu après son retour, l'alarme sonna l'arrivée de l'invasion américaine par le lac Champlain. Boucherville rejoignit alors son bataillon de milice, installé à Châteauguay, où il avait le rang de colonel et servait comme aide-major. Mais il ne participa pas à la célèbre bataille de Châteauguay, le 26 octobre 1813. Son bataillon était commandé par son beaufrère Chaussegros de Léry. Le jeune marchand resta à l'écart des grands événements. À la fin de 1813, la milice se retira dans ses quartiers d'hiver et Boucherville put se reposer. Rentré chez lui, il fit une pleurésie et fut malade tout l'hiver. Au printemps, il se rendit à Québec, où le rejoignit Quetton de Saint-Georges: «et nous eûmes beaucoup de plaisir ensemble dans les respectables familles que nous visitions" (JVB 149).

La guerre cessa en décembre 1814, mais Verchères de Boucherville ne jugea pas cet important événement digne de mention dans son Journal.

\section{VAINES tENTATIVES POUR REPRENDRE LE COMMERCE}

En janvier 1815, Boucherville se rendit à Kamouraska, où il passa deux jours chez le seigneur Taché. Il songea d'abord à reprendre à Amherstburg ses anciennes activités lucratives: "Mon intention était de m'en retourner à Amherstburg évacué par les $[A]$ méricains dès la guerre terminée, afin de m'assurer de ce qu'étaient advenu [sic] des marchandises, livres, billets, obligations et autres objets que j'y avait [sic] laissés. J'achetai quelques marchandises 
pour défrayer mon voyage et me fis venir de Repentigny un canot d'écorce [. .]» (JVB 151). Il partit au début de juin, dans un canot monté par six hommes, la plupart originaires de Boucherville: le bout était Paul Saint-Germain qui «chantait du matin au soir avec une verve réellement étonnante, ayant toujours des chansons nouvelles, mais toujours convenables à nous donner. Il était un modèle de voyageur sous ce rapport et beaucoup d'autres aussi. Son chant était cadensé [sic] sur le mouvement de l'aviron, aussi allions[-]nous avec une vitesse extraordinaire" (JVB 152). En dix jours, on était rendu à York: «En ligne droite, je me rendis chez M. De St. Georges».

À Amherstburg, les conditions étaient peu reluisantes: on voyait partout les ravages de la guerre, car tout avait été incendié et les champs avaient été dévastés. Boucherville fut par contre bien accueilli par des amis et par «un grand nombre de mes sauvages de 1812-13" (JVB 153). Les Amérindiens souhaitaient qu'il reprît son commerce. Lui, il en avait l'intention, "mais il fallait [s]'assurer avant tout, si le pays après avoir subi le fléau d'une guerre désastreuse, pouvait le supporter, l'alimenter" (JVB 153).

En arrivant, Boucherville entreposa ses effets dans le hangar de W. Duff et logea chez Maisonville, car son ancienne maison était en piteux état et malpropre. Il alla passer quelques semaines à Sandwich, mais n'osa traverser à Détroit, par crainte d'être arrêté pour l'affaire de Lewiston en 1811 (JVB 155). Il fit des réclamations pour pertes auprès d'un certain colonel James. Dans le HautCanada, en 1815-1816, les autorités avaient reçu 2884 requêtes (d'une valeur de $390152 £$ ); les commissaires responsables de l'examen de ces réclamations en acceptèrent pour $256815 £$. Certaines compensations ne furent versées qu'après de longs délais qui causèrent la ruine de plusieurs demandeurs. Mais le temps des réclamations était écoulé quand Boucherville voulut recevoir la valeur des 
marchandises perdues et pillées par les Américains. Il en parla à Jacques Baby et écrivit à William Claus. Ses réclamations étaient fondées et son commis Meloche l'aîné avait connaissance de la nature des marchandises et de leur sort. Tout cela valait 2000 louis, une perte qui produit le commentaire amer suivant: «Voilà ce que cette guerre m'a rapporté» (JVB 156).

En passant par York, lors de son retour, il arrêta naturellement pour revoir Quetton de Saint-Georges qui l'accompagna au Bas-Canada, à Boucherville, où le jeune marchand resta quelques jours en attendant des marchandises commandées en Angleterre. Pour les acquérir, Boucherville s'était mis en société avec Quetton de Saint-Georges. L'entreprise ne réussit pas bien: «La paix ayant été proclamée, le prix des marchandises tomba de beaucoup, même jusqu'à vingt-cinq pour cent du prix coûtant. Je lui [c'està-dire à Quetton de Saint-Georges] avais donné tout l'argent que je possédais. Je n'en étais pas fâché, mais cela me faisait voir les choses bien en noir, assurément» (JVB 158). Le voilà donc ruiné. C'est un sort que subirent plusieurs marchands. Quant à Saint-Georges, il «fit transporter ses marchandises à York et remit ses affaires entre les mains de MM. J. Quesnel et Baldwin, ayant formé le projet de repasser en France pour y aller embrasser son père" (IVB 158).

Plus tard en 1815, Boucherville tenta aussi d'établir un commerce dans son village natal. Il acheta une propriété et ouvrit une boutique (JVB 159). Mais les affaires allaient mal et il décida de retourner à Amherstburg en 1816: «Je me transportai donc avec ma marchandise en cette ville encore une fois" (JVB 159).

Boucherville tenta donc une dernière fois sa chance. À Niagara, il rencontra $\mathrm{M}^{\mathrm{gr}} \mathrm{J}$.-O. Plessis, le prélat étant en route vers Sandwich «avec toute sa suite». Une dernière fois, Boucherville traversa le lac Érié en bateau jusqu'à Amherstburg. Il ne put que mesurer la taille des obstacles 


\section{Verchères de Boucherville dans le Haut-Canada}

dressés devant lui. Il décida de se retirer des affaires et de confier les marchandises qui restaient à Meloche père. Après avoir pris son salaire, celui-ci devait remettre le profit à Boucherville. Ce dernier quitta donc Amherstburg «au beau milieu de juillet, mais non sans regret, car [il y avait] de sincères amis.» À propos des Amérindiens, Boucherville écrit: "Les sauvages me témoignèrent toute leur peine de me voir ainsi partir [. .]. Je leur fis un petit cadeau de dix piastres. Après mon départ, ils durent s'enivrer royalement là dessus!» (JVB 156). Plus loin, le Journal dit que c'est à Maisonville qu'il confia ses biens: «Tout ce dont je ne pus me défaire de ce que j'avais apporté avec moi, fut laissé aux mains de Maisonville. Je passai deux mois à Amherstburg et, cette fois, m'en éloignai pour toujours" (JVB 159).

En septembre 1816, Boucherville était de retour dans son village. Le Journal rapporte: «[je] continuai mon commerce ici, mais cela ne m'allait pas et je l'abandonnai en me délaissant de ma marchandise [sic] à Montréal» (JVB 160). Après avoir rapidement rapporté ces faits, le Journal s'arrête brusquement. La carrière marchande de Boucherville avait pris fin. Quant à Quetton de Saint-Georges, il continua en affaires, associé à John Spread Baldwin et à JulesMaurice Quesnel. Boucherville, lui, redevint un membre en vue de la petite noblesse canadienne.

\section{Conclusion}

Thomas-René-Verchères de Boucherville, dans son Journal, livre une page de l'histoire de l'Ontario au début du XIX ${ }^{e}$ siècle, écrite par le fils d'une famille canadienne appartenant à la petite noblesse. Il montre que la traite des fourrures avait à cette époque, tant dans le Nord-Ouest que dans le Sud-Ouest, encore une place. Par la traite des fourrures, Boucherville continuait la longue association de sa famille avec la région des Grands Lacs. 
Les activités de Verchères de Boucherville nous révèlent aussi certains aspects de la pratique du commerce de détail, avec ses structures de transport, d'approvisionnement et de financement. Le témoignage de ce marchand permet d'entrevoir le rouage d'une partie du commerce de détail dans le Haut-Canada au début du XIX ${ }^{\mathrm{e}}$ siècle. Dans le cas de Boucherville, l'approvisionnement de son comptoir était occasionnel, à cause des distances. À Amherstburg, à en juger par le Journal, tout semble se payer comptant. Mais le crédit jouait un rôle important quand Quetton de SaintGeorges garantit les achats de son protégé. On peut ainsi faire de grands coups d'argent, comme on peut tout perdre par un jeu de circonstances.

Les données contenues dans le Journal ne permettent pas de mesurer l'ampleur de la richesse de ces marchands. Une partie de la fortune constituée par de Boucherville et par Quetton de Saint-Georges provenait de compensations pour pertes durant la Guerre de 1812. L'un et l'autre avaient accumulé de grands profits en 1812 et 1813 quand la hausse des prix les avait grandement avantagés. Mais Boucherville avait apparemment tout perdu en 1815 avec l'affaissement des prix. Désormais, il chercha des compensations en demandant au gouvernement soit de l'argent, soit des terres.

Le Journal reproduit des lettres d'appui de M.C. Muir (1820) et de William Claus (1823) en faveur de Boucherville. Jacques Baby lui écrivit en 1824 une lettre disant que les commissaires vont lui accorder 500 louis. Une autre lettre, au caissier (paymaster) de l'armée, James Gordon, en juillet 1827, répond que le gouvernement ne peut accéder à la requête de Boucherville qui a demandé des terres au Bas-Canada pour ses services de milice. Enfin, une nouvelle requête fut soumise à la Reine en 1851, par l'entremise de lord Elgin, avec des lettres d'appui de I'honorable James Gordon et de Jean-Baptiste-René Hertel de Rouville pour faire reconnaître les services du requé- 
rant. Pour ses efforts, Boucherville reçut une médaille des mains du colonel Melchior-Alphonse de Salaberry, fils de Charles-Michel d'Irumberry de Salaberry.

Au début du XIX ${ }^{e}$ siècle, le déclin de la noblesse canadienne continuait. Pour maintenir son statut et trouver des places à ses enfants, ce groupe social s'allia à d'autres familles appartenant à la noblesse, à l'armée ou à la grande bourgeoisie marchande. On peut voir cette stratégie à l'œuvre dans le comportement de Verchères de Boucherville. Partout où il le peut, il rencontre, salue ou rend visite aux personnes en vue du monde gouvernemental, militaire, économique. Lors de son séjour dans la région de Sandwich et d'Amherstburg, ce cadet de la noblesse canadienne s'inséra dans la bonne société, rencontrant le lieutenantgénéral Gore, ou des bourgeois importants du commerce des fourrures, ou la famille influente des Baby. Mieux, on trouve dans la région de Sandwich-Amherstburg un noyau de Canadiens qui semblent jouer un rôle important. Ils s'occupent du commerce des fourrures et du commerce de détail, font de la spéculation foncière ou remplissent diverses fonctions gouvernementales. Ils font partie de l'élite locale. Le Journal laisse entrevoir l'existence de ce groupe. Le Journal nomme les Baby (Jacques, François, Jean-Baptiste), Frédéric Rolette, Alexis Maisonville, J.-B. Barthe, JeanBaptiste Cadotte et son frère, Alexis Bouthillier. Ce groupe de Canadiens est important et influent. Il comprend plusieurs jeunes, comme Verchères de Boucherville, qui cherchent à se faire accepter comme ils le feraient dans le Bas-Canada. Leur nombre et leur rôle restent peu connus.

Selon le Journal, Boucherville aurait tout perdu les sommes obtenues dans son commerce lucratif d'Amherstburg. Quetton de Saint-Georges semblait aussi ruiné, mais tel n'était pas le cas puisqu'il se retira en France, après quelques années, avec une cagnotte de $20000 £$ (cours d'Halifax), une somme qui lui permit de s'établir. 
En se mariant en 1819 , Verchères de Boucherville renonçait définitivement à ses activités commerciales. Il nota dans son Journal: «En changeant d'état, je restais cependant citoyen-propriétaire dans ma paroisse natale, mais ne pouvais m'empêcher de regretter tout-à-fait [sic] la partie ouest du Haut-Canada où s'étaient coulées des années si mouvementées pour moi» (JVB 160).

Boucherville mourut le 13 décembre 1857, après avoir mené, non une carrière de marchand dans le HautCanada, mais une vie de seigneur dans le Bas-Canada.

* L'auteur tient à remercier ses collègues de la Société Charlevoix, et au premier chef Fernand Ouellet, de même que ses confrères de l'Université Laurentienne, les professeurs Gratien Allaire et Guy Gaudreau. Ils ont lu une première version de ce texte et fait d'utiles suggestions pour l'améliorer. 